\title{
Wave Transformation and Wave-Driven Flow across a Steep Coral Reef
}

\author{
STEPHEN G. MONISMITH AND LIV M. M. HERDMAN \\ Environmental Fluid Mechanics Laboratory, Stanford University, Stanford, California \\ SOEREN AHMERKAMP \\ MPI for Marine Microbiology, Bremen, Germany \\ JAMES L. HENCH \\ Environmental Fluid Mechanics Laboratory, Stanford University, Stanford, California, and Nicholas School \\ of the Environment Marine Laboratory, Duke University, Beaufort, North Carolina
}

(Manuscript received 6 September 2012, in final form 11 January 2013)

\begin{abstract}
Observations of waves, setup, and wave-driven mean flows were made on a steep coral forereef and its associated lagoonal system on the north shore of Moorea, French Polynesia. Despite the steep and complex geometry of the forereef, and wave amplitudes that are nearly equal to the mean water depth, linear wave theory showed very good agreement with data. Measurements across the reef illustrate the importance of including both wave transport (owing to Stokes drift), as well as the Eulerian mean transport when computing the fluxes over the reef. Finally, the observed setup closely follows the theoretical relationship derived from classic radiation stress theory, although the two parameters that appear in the model-one reflecting wave breaking, the other the effective depth over the reef crest—must be chosen to match theory to data.
\end{abstract}

\section{Introduction}

Dating back to the pioneering work of Munk and Sargent (1948), it is been long appreciated that surface wave breaking is a primary mechanism for driving flows over coral reefs (see also Symonds et al. 1995; Gourlay 1996). The dynamical basis by which waves force flows is similar to that by which alongshore flows are driven on beaches: wave breaking produces spatial gradients in radiation stresses that act as body forces on the flow (Longuet-Higgins and Stewart 1964). These forces are primarily balanced by friction in the case of waves on beaches (Ruessink et al. 2001) or by free surface pressure gradients in the case of flow over reefs (Symonds et al. 1995 Bonneton et al. 2007; Lowe et al. 2009a; Vetter et al. 2010). An important difference between the two cases is that the net transport normal to beaches is zero whereas the net transport normal to barrier-type reefs is often

Corresponding author address: Stephen G. Monismith, Dept. of Civil and Environmental Engineering, Stanford University, 473 Via Ortega, Stanford, CA 94305-4020.

E-mail: monismith@stanford.edu nonzero. In the former case, the forcing of alongshore flows is due to turning of the waves during shoaling and breaking whereas, in the latter case, shoaling normal to the reef can drive cross-shore flows.

In its simplest form for steady one-dimensional waveaveraged flow, the dynamics of wave-driven flows can be described by the depth-averaged momentum equation (cf. Hearn 1999; Gourlay and Colleter 2005; Mei et al. 2005)

$\frac{d}{d x}\left(\frac{q_{T}^{2}}{h+\langle\eta\rangle}\right)=-g(h+\langle\eta\rangle) \frac{d\langle\eta\rangle}{d x}-\frac{1}{\rho} \frac{d S_{\mathrm{xx}}}{d x}-\frac{C_{D}\left|q_{E}\right| q_{E}}{(h+\langle\eta\rangle)^{2}}$

where $h(x)$ is the local depth in the absence of waves, and $\langle\eta\rangle$ is the wave-averaged deviation of the free surface $\eta$ from its mean position, and $C_{D}$ is the drag coefficient (Fig. 1). The total transport $q_{T}$ is apportioned between the mean Eulerian flow $q_{E}$ and the Stokes or wave transport $q_{s}$. These are defined in the appendix as are other wave quantities such as the radiation stress $S_{\mathrm{xx}}$, a quantity that represents the average effects of the waves on the mean flow momentum (Longuet-Higgins 
and Stewart 1962,1964). Consistent with the steady 1D momentum equation above, continuity integrates to the simple statement that $q_{T}$ is constant.

To close the wave-averaged momentum and continuity equations it is necessary to specify the wave field. In many numerical models (e.g., Booij et al. 1999) this is done assuming linear waves propagating over a nearly flat bottom such that conservation of wave action (e.g., Roelvink et al. 2009) can be used to compute wave amplitudes, which can in turn be used via constant depth, linear wave theory to compute radiation stresses and wave transport. Given that wave-induced velocities are generally much less than phase speeds, it can be assumed that there is little Doppler shifting of the wave frequency, and so conservation of wave action reduces to conservation of wave energy:

$$
\frac{\partial}{\partial x}\left(F_{w}\right)=-\varepsilon
$$

where the shore-normal component of the wave energy flux is

$$
F_{w}=c_{g} E \cos (\theta)
$$

where $c_{g}$ is the group velocity, $E$ is the wave energy density, $\theta$ is the angle between the wave rays and the shore-normal direction, and $\varepsilon$ is the wave dissipation. These quantities are also defined in the appendix.

Finally, to complete the wave model, a representation of wave breaking is required. A number of different models are in use for waves on beaches; of these, the simplest is one for which the local wave height $H$ is limited to some fraction $\gamma$ of the local depth (Raubenheimer et al. 1996):

$$
H=\gamma h .
$$

More sophisticated models of breaking are generally used in current nearshore models (see e.g., Roelvink et al. 2009); however, given that these are quasi empirical and based on observations of breaking on relatively mild beach slopes (ca. 1\%-5\%) with wide surfzones, their utility on steep bottoms $(>10 \%)$ common to coral forereefs may be questionable. Indeed Yao et al. (2013) show breaking on reef geometries can be quite different from what is observed on flat beaches. Nonetheless, in their modeling study, Filipot and Cheung (2012) found that (4) was more appropriate for steep tropical reefs than were more complicated models taking into account reef slope, etc.

If the forereef wave dissipation, mean flow drag, and advective accelerations are all small, then (1) can be integrated from the outer edge of the surfzone, defined by shoaling and the breaking condition (4), to the reef flat, where the local depth is $h_{r}$ to determine the wave setup (e.g., Tait 1972; Vetter et al. 2010):

$$
\langle\eta\rangle_{r} \approx \frac{3 \gamma^{2}}{8+3 \gamma^{2}}\left[\frac{\left(8 F_{w} / \rho\right)^{2 / 5}}{g^{3 / 5} \gamma^{4 / 5}}-h_{r}\right]=A\left(\frac{F_{w}}{\rho}\right)^{2 / 5}-B .
$$

Equation (5) only applies when $\langle\eta\rangle_{r}>0$, that is, when waves break somewhere before the reef flat. If $F_{w}$ can be estimated using the significant wave height $H_{s}$ and period $T_{s}$ measured offshore (Vetter et al. 2010), then $\langle\eta\rangle_{r} \propto H_{s}^{m} T_{s}^{m}$, where $m=0.8$ and $n=0.4$. Using $\gamma=0.9$ Vetter et al. (2010) found good agreement between (5) and their observations of wave setup on the reef at Ipan, Guam, for a wide range of values of $F_{w}$ including very large, cyclone-generated waves. In contrast, Lowe et al. (2009a) found large variability in $m$ and $n$ for different sections across Kaneohe Bay, although, since the setups were smaller, uncertainty concerning the absolute water level measured by the pressure sensors may make clear determination of the setup difficult (see below). Hench et al. (2008) found values of $m$ and $n$ that were quite different from what standard theory gives, but these values may be biased by one event with exceptionally long period waves $(T>20 \mathrm{~s})$ for which the setups were substantially larger, and the measurement points that included a significant section of backreef inshore of the surfzone.

As the observations shown below demonstrate, inshore of the surfzone, the radiation stress gradient is much smaller than the free surface pressure gradient such that the latter is balanced by the shear stress gradient. In previous work at Moorea, Hench et al. (2008) found that $C_{D} \approx 0.1$ for the backreef lagoon, a value that they argued reflected the effects of drag from massive coral colonies (height and diameter $\sim$ depth) present in the lagoon rather than bottom surface roughness. Thus, to first order the overall model of wave-driven flow is that surfzone setup determines the pressure gradient, and drag determines the flow that this pressure gradient produces (see Lowe et al. 2009a). One significant problem with this in terms of prediction is that $C_{D}$ is difficult to specify a priori (cf., Rosman and Hench 2011).

The physics described in equations above have been explored in two spatial dimensions by several authors (e.g., Lowe et al. 2009b; Symonds et al. 2011), who have generally found reasonable agreement between observations and model results. Following up on the simple analytical model of Lowe et al. (2009b), Lowe et al. (2010) explored the effects of reef morphology on wave-driven flow, showing how resistance in the reef passes, regions where the inflow over the reef returns to the ocean, can limit the overall flow over and through the reef. 


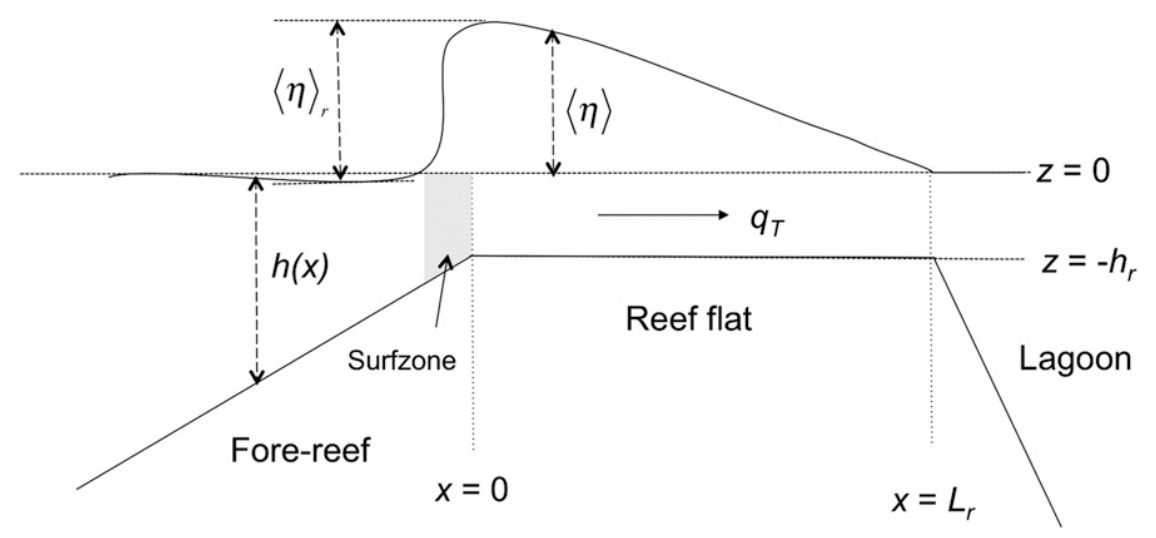

FIG. 1. Definition sketch for wave-averaged flow across a coral reef and lagoon system.

In summary, it would appear that a first-order description of wave-driven flows over reefs using relatively simple ideas about the waves has emerged. However, there are good reasons to question the limits of that description. First, the forereef slopes at Kaneohe Bay (Lowe et al. 2009a,b) or Ningaloo (Taebi et al. 2011) are relatively flat compared to many Pacific reefs that can have slopes of $10 \%$ or more. Moreover, as we show below, waves on the forereef can be quite steep. Thus, it is an open question as to whether or not wave models based on small amplitude waves over nearly flat bottoms are appropriate.

Alternatively, Boussinesq models (e.g., Nwogu and Demirbilek 2010) can be employed that represent both nonlinearity and weak dispersion and explicitly produce predictions of setup, although they are best suited for narrow-banded spectra and, in general, are formulated for nearly flat bottoms. These alternatives are relatively complicated and have not yet been incorporated into practical large-scale wave-circulation models. Thus, it remains of value to test the utility of simpler theories.

In this paper, we will present observations of waves, setup, and wave-driven mean flows on a fringing reef on the north shore of Moorea, French Polynesia (FP). Despite the steep and complex geometry of the forereef, and wave amplitudes that are nearly equal to the mean water depth, linear theory works surprisingly well. Our measurements of flow across the reef make clear the importance of including both the wave transport (Stokes drift transport), as well as the Eulerian mean flow when computing the flow over the reef. Finally, the setup we observe closely follows the theoretical relationship in (5), although two parameters, $\gamma$ and $h_{r}$, must be chosen to match theory to data.

\section{Methods}

Beginning in 2003, one of us (JLH) began measuring waves and currents near Paopao Bay on the north shore of Moorea, French Polynesia (17²8.48' S, $149^{\circ} 50.39^{\prime} \mathrm{W}$; Fig. 2); early results from this work are presented in Hench et al. (2008). Tides and wind-driven flows are generally relatively weak so that generally waves provide the major driving force for currents over the reef crest, through the shallow backreef lagoon and back out the deep reef pass.

Starting in late 2006 and continuing intermittently through early 2009, a cross-reef array of current profilers and pressure sensors were deployed (Fig. 2). These measurements were enhanced with a series of shortterm deployments of pressure loggers [Richard Brancker Research, Ltd. (RBR), (DR-1050), Teledyne RD Instruments ADCPs, and Nortek acoustic Doppler profilers (ADPs)]. Table 1 shows a timeline of the various deployments. In this paper we will focus on the measurements made between 8 and 22 February 2009, for which we had a relatively complete set of measurements along the line from station FR20 and P7 (Fig. 2). We will also include a more limited view of similar measurements taken in February 2006, between December 2008 and January 2009, and the spring of 2010, which coincided with a large tropical cyclone. All instruments were attached to plates that were fixed to the bottom by rods epoxied into the reef. Figure 2 also shows the basic geometry of the reef, in particular the $\sim 15$-m-wide reef crest that rises to approximately coincide with the mean water level in the absence of waves. It should be noted that strictly speaking $h_{r} \approx 0$. However, in light of the laboratory measurements of Yao et al. (2009) who examined in the laboratory the complex flow dynamics possible near such a ridge on steep reef faces, in the setup measurements shown below we will treat $h_{r}$ as a fitting parameter.

For the February 2009 measurements, 1.2-MHz ADCPs at forereef stations $\mathrm{P} 1$ and $\mathrm{P} 2$ recorded single ping velocity and pressure data at $1.79 \mathrm{~Hz}$ with $0.25-\mathrm{m}$ bins and using 6 mode- 12 subpings to reduce single ping uncertainty. The 2-MHz ADPs at stations P2.5, P3, P4, P5, 

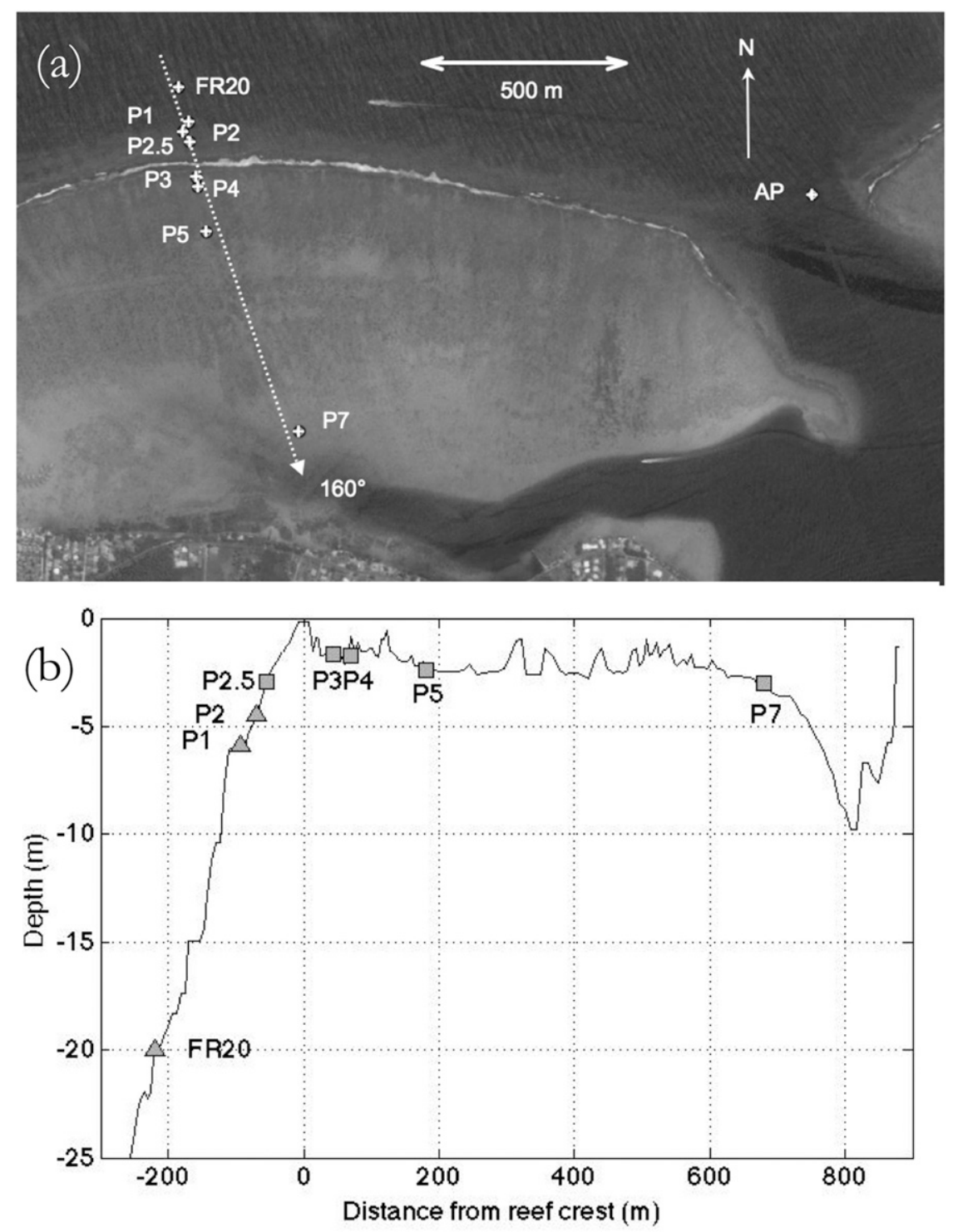

FIG. 2. Layout of measurement stations at Paopao Bay, Moorea, FP during the 2006-09 experiments: (a) instrument array locations spanning the forereef, reef crest, backreef, lagoon, and reef pass (image from Google Earth); (b) cross-reef section along transect from FR20 to P7 showing instrument locations and reef bathymetry.

and P7 alternatively sampled in two modes: (i) a wave burst at $2 \mathrm{~Hz}$ of 2048 samples of pressure and velocity taken once per hour in a single bin $75-\mathrm{cm}$ high centered $60-\mathrm{cm}$ above the bed; and (ii) mean current profiles measured at $1 \mathrm{~Hz}$ recorded as 60 -s averages for times other than when the wave-burst mode was active. RBR DR-1050 pressures sensors were collocated with each of the instruments and sampling and recording at $1 \mathrm{~Hz}$. Based on inspection of spectra shown below (Fig. 3), wave averaging was done using a fourth-order Butterworth filter with a cutoff frequency of $0.02 \mathrm{~Hz}$. Comparison of the pressure variations from all pairs of instruments indicated that waves derived from the pressure sensors on the current meters agreed to within a few percent of those inferred from the RBR pressure loggers. Accordingly, wave properties were inferred from the pressure logger data and wave velocity properties were determined from the pressure sensors on the current meters. Moreover, given that the pressure sensor ports for the various instruments are located in different places and face different directions on very different shaped bodies suggest that contamination of the pressure measurements by 
TABLE 1. Moorea deployment dates and locations. Station FR20 had a $600-\mathrm{kHz}$ ADCP, P1 and P2 had 1.2-MHz ADCPs, and stations $\mathrm{P} 3-\mathrm{P} 7$ had 2-MHz ADPs.

\begin{tabular}{ll}
\hline \hline \multicolumn{1}{c}{ Dates } & \multicolumn{1}{c}{ Stations } \\
\hline 7 Dec 2006-21 Feb 2007 & FR20, P1, P2, P3, P4, P5, P6, P7, AP \\
1 Dec 2008-31 Jan 2009 & FR20, P1, P2, P2.5, P3, P4, P5, P7, AP \\
8 Feb 2009-22 Feb 2009 & FR20, P1, P2, P2.5, P3, P4, P5, P7, AP \\
18 Dec 2009-1 May 2010 & FR20, P5 \\
\hline
\end{tabular}

dynamic pressures was minimal (cf. Raubenheimer et al. 2001).

The onshore wave energy flux includes the effect of directionality of the incident wave field [cf. (3), (A9), and (A10)]. For the February 2009 data, this was done using the PUV method as outlined in Gordon and Lohrmann (2001) to compute the principal direction for each frequency from the ADCP and ADP data and so to compute $F_{w}$ using (A10). For the longer dataset discussed below that includes cyclone Oli, the only available data source for the offshore energy flux was the 20-m ADCP, which operated in Teledyne RDI's waves mode and sampled at $2 \mathrm{~Hz}$ for $20 \mathrm{~min}$ every $3 \mathrm{~h}$. For these data, directional wave spectra estimates were computed using Teledyne RDI's waves software (Strong et al. 2000), with the total shoreward energy flux computed by integration using (A9).
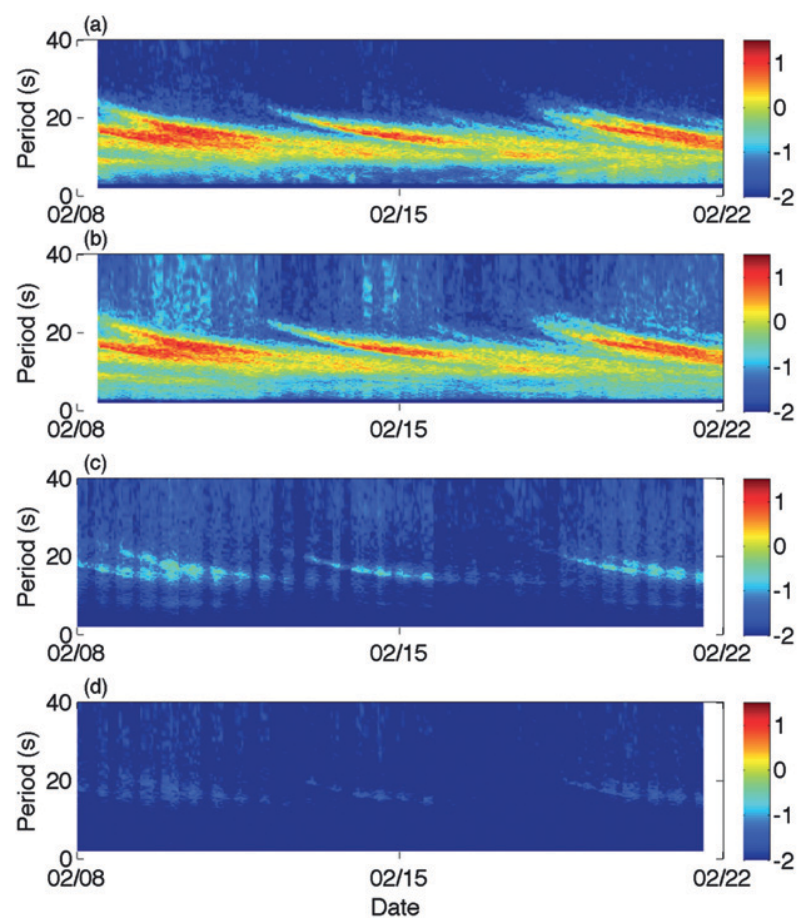

\section{Observations of the waves}

As discussed in Hench et al. (2008), large wave events on the forereef of the north shore of Moorea during the Austral summer are largely remotely generated swell from storms in the North Pacific. Spectrograms of waves observed at four stations across the reef crest (Fig. 3) share several features. First, some of the most energetic wave events correspond to periods where waves from two separate storms overlap. Despite this, the overall pdf of wave heights incident to the reef (not shown) adheres closely to the Rayleigh distribution (e.g., Holthuijsen 2007). Second, at the forereef stations water level variability is dominated by gravity wave $(2<T<20 \mathrm{~s})$ energy whereas, inshore of the surfzone, infragravity waves $(T>50 \mathrm{~s})$ dominate (cf. Sheremet et al. 2002; Péquignet et al. 2009), although at station P2.5, the most shoreward forereef station, infragravity wave energy is increased relative to the station, $\mathrm{P} 1$, located approximately $40 \mathrm{~m}$ farther offshore. Tidal modulation of the wave field, evidently associated with changes in water depth over the top of the reef crest, is apparent at all but the most offshore station. The reef crest also appears to partially isolate the offshore and onshore wave fields in that coherence of the free surface variations between fore reef stations, for example, $\mathrm{P} 2$ and $\mathrm{P} 2.5$ and between back reef stations, for example, $\mathrm{P} 3$ and $\mathrm{P} 4$ tends to be between 0.8 and 1 for most frequencies, whereas the coherence
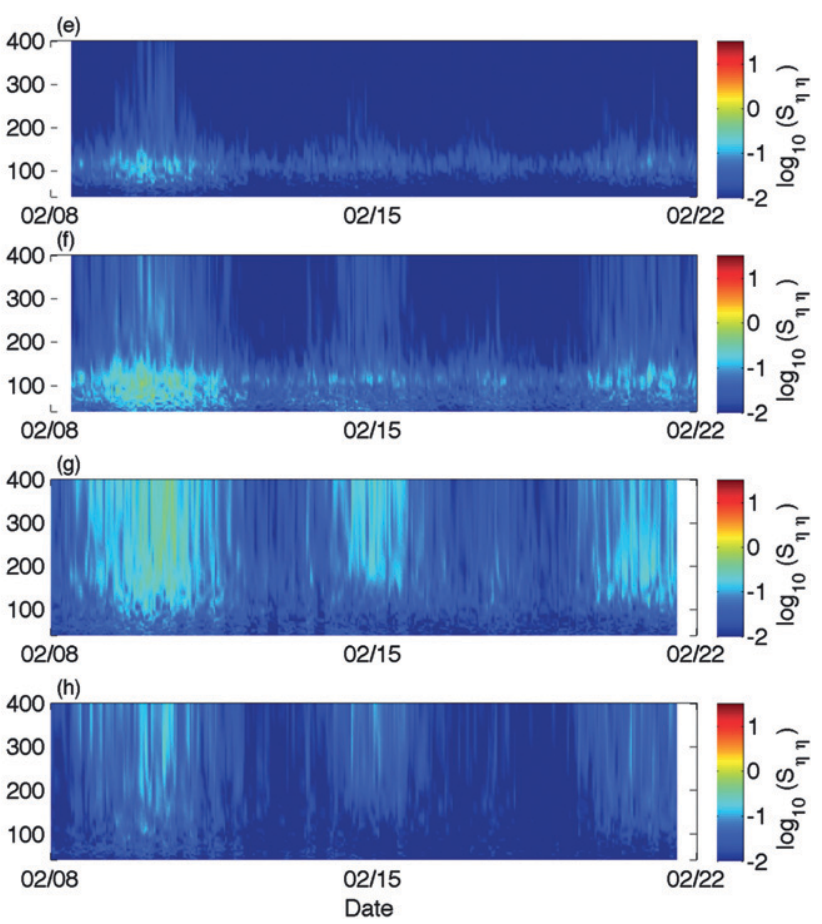

FIG. 3. Spectrograms of free surface elevation computed in 2.28-h windows: (left) gravity wave spectrum ( $T<40 \mathrm{~s}$ ) for stations (a) P1, (b) P2.5, (c) P3, and (d) P5. (e)-(h) The infragravity wave portion of the spectrum $(40<T<400$ s) for the same stations. 
(a)

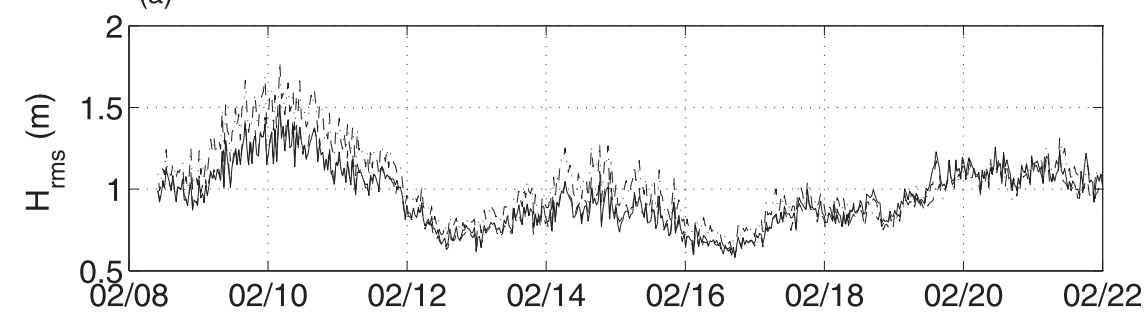

(b)

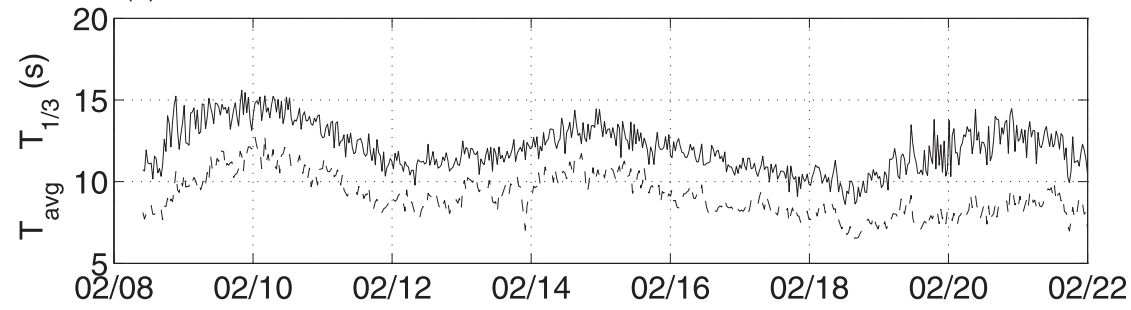

(c)

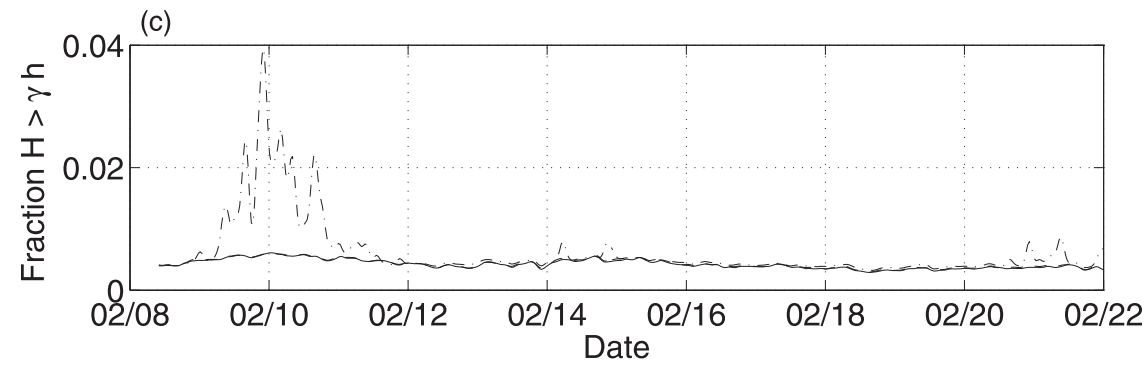

FIG. 4. Wave conditions for the February 2009 deployment: (a) $H_{\mathrm{rms}}$ at P1 (solid line), P2 (dashed line), and P2.5 (dash-dotted line); (b) wave periods for forereef derived by wave counting- $T_{1 / 3}$ (solid line) and $T_{\text {avg }}$ (dashed line); and (c) fraction of waves at P1, P2, and P2.5 for which $H \geq \gamma h$ with $\gamma=0.98$, that is were likely to be breaking [symbols as in (a).]

between stations on different sides of the ridge (e.g., P2.5 and P3) is much lower (ca. 0.4-0.6).

In general, the incident waves at our inner stations propagate nearly normal to the reef crest, with directional variations of the incident swell generally less than $10^{\circ}$ away from normal to the reef (Herdman 2012). One exception to this behavior was seen during the last few days of the February 2009 experiment during which time the wave field was a superposition of long (10-20s) swell propagating normal to the reef and short waves $(5-8 \mathrm{~s})$ propagating at about $25^{\circ}$ to the west of normal, somewhat as can be seen in Fig. 2. The effect on the shoreward energy flux was a maximum reduction of the incident flux to $85 \%$ of what would be computed if all of the flux was directed shore normal. However, as will be seen in the fitting of (5) shown below in section 5, directional variations seem to have little effect on the prediction of setup.

Temporal variability of forereef rms wave heights $H_{\mathrm{rms}}$ and periods, both the average period $T_{a}$ and the significant period $T_{s}$, all determined by examination of single waves and averaged for 2048-s-long sections of the data (Fig. 4) are consistent with the Rayleigh distribution $H_{\mathrm{rms}} \simeq H_{s} / \sqrt{2}$. Additionally, $H_{\mathrm{rms}}$ determined from the statistics of individual waves is close to $2 \sqrt{\left\langle\eta_{w}^{2}\right\rangle}$, that is, the rms wave height determined from the wave variance. In contrast, reflecting the varying spectral content of the incident wave field $T_{s} / T_{a}$ varied during the record from 1.2 to 1.6.

As expected from shoaling, inshore wave amplitudes were generally larger than those offshore. To examine the likelihood that waves were breaking, we have also plotted the fraction of waves at each station for which $H>\gamma h$ (Fig. 4c) where based on the setup results (section 5), we have chosen $\gamma=0.98$. Interestingly, a manual examination of the wave records reveals that every wave at P1 $(h=6 \mathrm{~m})$ for which $H>\gamma h$, appeared to have broken by the shoreward station, P2.5 $(h=3 \mathrm{~m})$, which is approximately $1 / 2$ wavelength shoreward of P1 (Fig. 5a), whereas waves were observed for which $H<\gamma h$ at $\mathrm{P} 1$ but had $H>\gamma h$ at $\mathrm{P} 2.5$ (Fig. 5b). Thus, as suggested by previous laboratory experiments (Yao et al. 2013), it would appear that, on the steep Moorea reef, breaking may not be well described by the normal beach breaking models that posit a quasi-equilibrium, albeit highly dissipative, structure. 
(a)

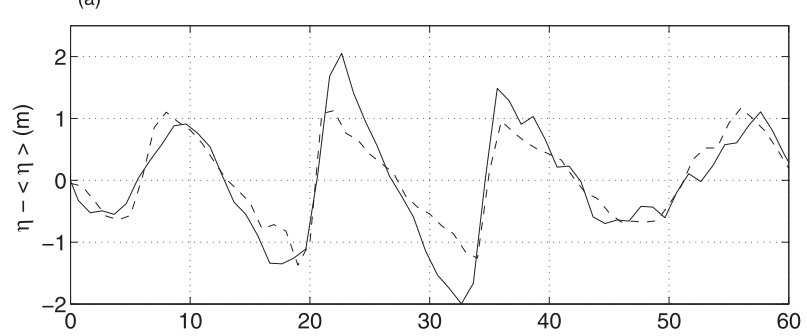

(b)

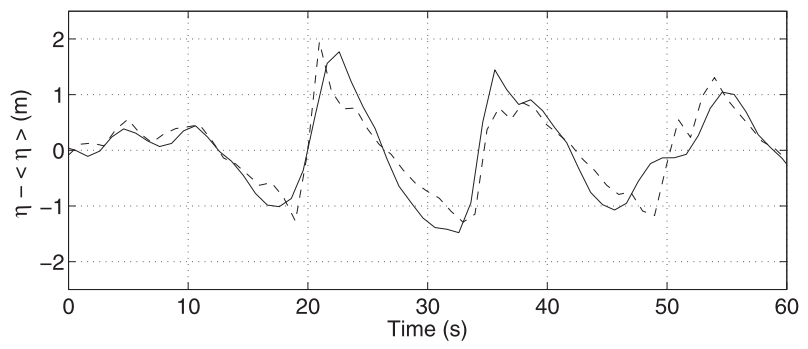

FIG. 5. Example wave-group behavior. In (a), the steep $(H / h \simeq$ 0.67 ) wave at the front of the group at P1 (dashed line) has broken by P2.5 (solid line); whereas in (b), the tallest wave at the front of the group at $\mathrm{P} 1$ has steepened to $H / h \simeq 1$ at $\mathrm{P} 2.5$ and may be breaking.

In any case, it is clear that the waves observed at the forereef stations were quite steep, with $0.15<H_{\text {rms }} / h<$ 0.45 or $0.2<H_{s} / h<0.7$. Using linear wave theory to estimate the wavelength $\lambda$ at each station as a function of $T_{a}$, mean values of the Ursell number, $U=H \lambda^{2} / h^{3}$ at $\mathrm{P} 1$, $\mathrm{P} 2$, and $\mathrm{P} 2.5$ were 19,41 , and 175 , respectively.

Instantaneous wave velocities at the forereef station closest to the reef crest (P2.5) were quite high, up to $3 \mathrm{~m} \mathrm{~s}^{-1}$ and for which $H \approx h$ (Fig. 6). Nonetheless, despite the steepness of the reef face and the highly nonlinear waves, the observed velocities (Fig. 6b) conform quite closely to linear wave theory in (5). Low-pass-filtered elevations (Fig. 6c) show the approximately 100-s period oscillation that dominates the infragravity wave response. The low-pass-filtered velocities (Fig. 6d) also show considerable variability over the total period of the burst, and remarkably show that the mean Lagrangian velocity is quite close to the depth-averaged Stokes drift velocity, implying that the mean Eulerian velocity is nearly zero. This behavior will be examined further below.

Comparison of instantaneous velocities with linear shallow water wave prediction, (A4), for the entire record (Fig. 7a) shows that on average crest velocities $>1 \mathrm{~m} \mathrm{~s}^{-1}$ (a velocity that corresponds to $\eta_{w} / h \simeq 0.2$ ) are less than what the simple theory gives, while those $<1 \mathrm{~m} \mathrm{~s}^{-1}$ correspond quite well to linear theory. Nonetheless, even a significant fraction of the raw velocities appear to match linear theory with surprising accuracy (Fig. 7a), even for quite steep waves $(H / h \approx 1)$. This may be due to the fact that the average behavior reflects the superposition of both unbroken and broken waves. Thus, to first order, wave velocities were well described by simple linear theory, despite the fact that free surface displacements were decidedly nonsinusoidal. This behavior is similar to that of surfzone waves on planar beach geometries (e.g., Guza and Thornton 1980).

To further test the utility of linear wave theory, one can compare observations of two wave-averaged quantities, wave transport and radiation stress with theory (Figs. 7b, c). The wave transport was calculated using (A1) and the radiation stress was computed using (A3). An approximation to $w$ was made using the linear free surface kinematic boundary condition and the assumption of a shallow water velocity field,

$$
w(z, t) \simeq[z /(h+\langle\eta\rangle)]\left(\partial \eta_{w} / \partial t\right),
$$

which gives

$$
\int_{-h}^{\eta} w^{2} d z \simeq \frac{h+\eta}{2}\left(\frac{\partial \eta_{w}}{\partial t}\right)^{2} .
$$

Least-squares fitting shows (Fig. $7 \mathrm{~b}$ ) that $q_{w}$ is $94 \%$ of what would be inferred from linear wave theory. The quantity $S_{\mathrm{xx}}$ is similarly well predicted by linear theory with observed values being $98 \%$ of theoretical values (Fig. 7c). The close correspondence of observations and theory near the surfzone seems to provide good support for the use of simpler theories of wave setup dynamics, at least for quasi-steady conditions.

Forereef flows observed at P2.5 also show that virtually all of the shoreward transport is carried by the wave transport $\left(\left\langle u \eta_{w}\right\rangle\right)$ since the mean cross-reef Eulerian velocity was nearly zero (Fig. 6d). In contrast, the alongreef flow was nonzero. The flow along the forereef face is likely to involve a pressure gradient-friction balance (Symonds et al. 2011) and so should be dependent on wave effects on friction as would be expected from extent theories of wave-current interaction (e.g., Grant and Madsen 1979). While the ADP does not provide direct measurements of turbulent stresses, mean Eulerian velocity profile data acquired by ADP can be used to infer stresses via log fitting:

$$
\frac{U_{E}\left(z^{\prime}\right)}{\bar{U}_{E}}=\frac{C_{D}^{1 / 2}}{\kappa} \log \left(\frac{z^{\prime}}{z_{0}}\right),
$$

where the overbar indicates averaging over depth. The results of fitting all of the average velocities for each mean profile burst give $C_{D}=0.1$ and $z_{0}=0.44 \mathrm{~m}$ (Fig. 8). Binning the data by $H_{\text {rms }}$ (as a proxy for orbital velocity) does not show any particular dependence on wave 


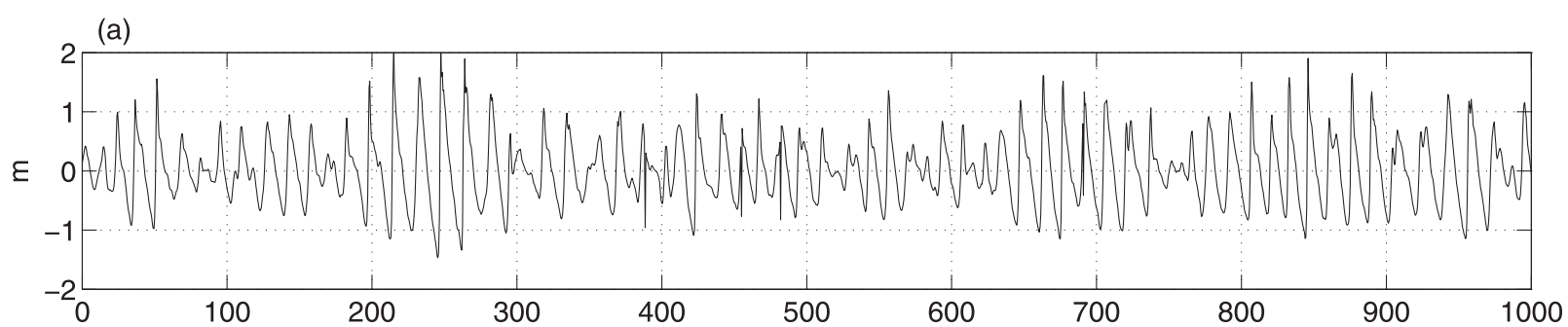

(b)

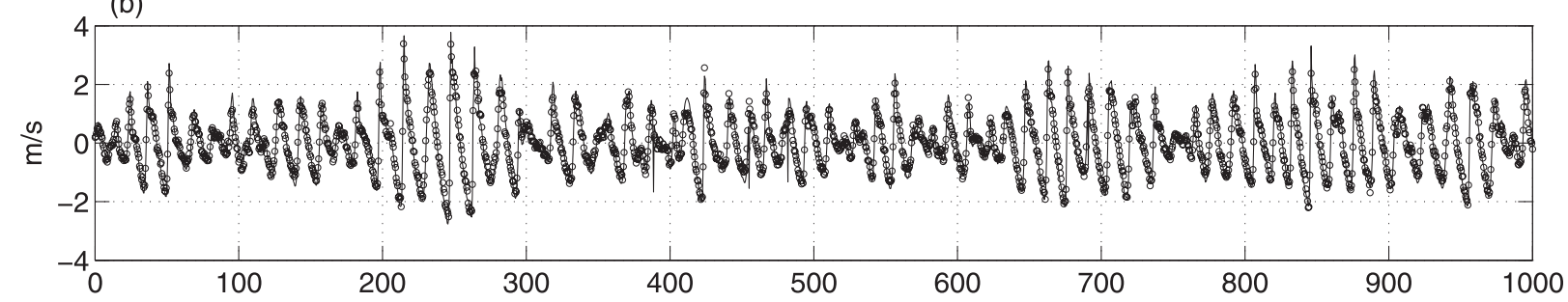

(c)

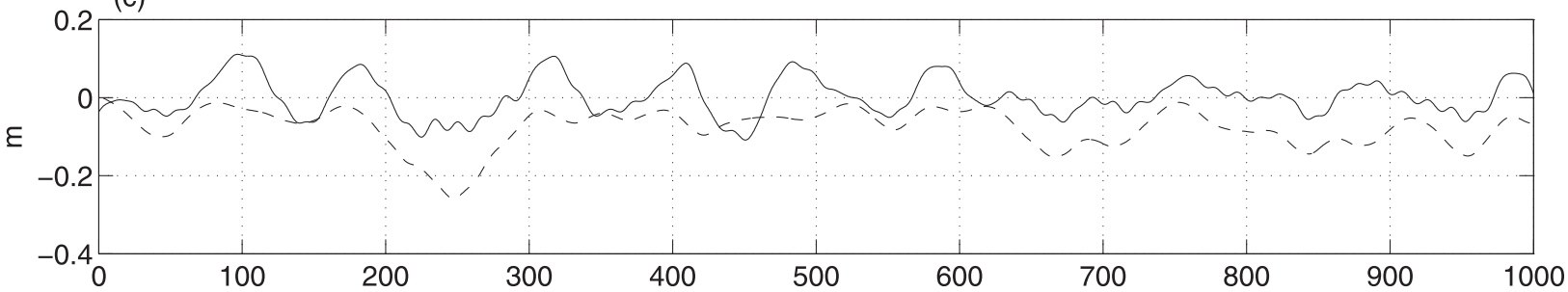

(d)

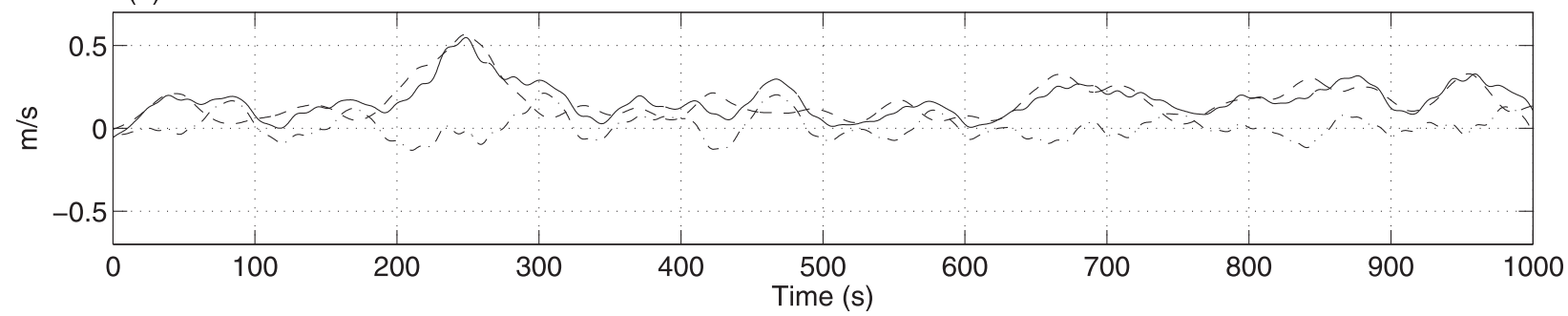

FIG. 6. Example 1024-s wave burst of data at P2.5 (a) High-pass-filtered free surface elevation and (b) observed high-pass-filtered (wave) cross-shore velocity (open circles) and linear shallow water theory using the time series in (a) (solid line). (c) Low-pass-filtered free surface and (d) low-pass-filtered depth-averaged velocities [Lagrangian (solid line), Stokes drift (dashed line), and Eulerian (dash-dotted line)].

properties, suggesting that alongshore drag on the forereef is more strongly determined by something other than waves; one possibility is form drag from $O$ $(100 \mathrm{~m})$ spur and groove structure perpendicular to the alongshore flow. Such behavior would be consistent with the remarkably large value of $z_{0}$ inferred by fitting. However, given that P2.5 was on the flat top of a reef spur (as were $\mathrm{P} 1$ and $\mathrm{P} 2$ ), this hypothesis remains to be fully tested by future work that resolves more of the horizontal variability of the forereef flow.

In contrast to the ADP at P2.5, which only measures velocity at one height during wave bursts, ADCPs at stations P1 and P2 provided profiles of horizontal and vertical wave-induced velocities, since the beam separation in shallow water (ca. 3-6 m) was much less than inferred wavelengths (ca. $100 \mathrm{~m}$ ). Velocities measured at these stations again show a remarkable correspondence to linear shallow water theory for both $u$ and $w$ (Fig. 9). For the entire record at $\mathrm{P} 2$ the rms depth-averaged horizontal velocity was within $1 \%$ of the linear shallow water velocity given by (A7) $\left(r^{2}=0.95\right)$.

Given the availability of velocity profiles that extend throughout most of the water column, including the region between individual wave troughs and crests, it is of interest to determine the extent to which the velocity structure matches flat bottom theory. This is made challenging by the nonlinearity of the waves, in particular the fact that local depths varied by up to $50 \%$ during the most energetic wave periods and so using a fixed Cartesian coordinate system to describe the vertical structure is 
(a)

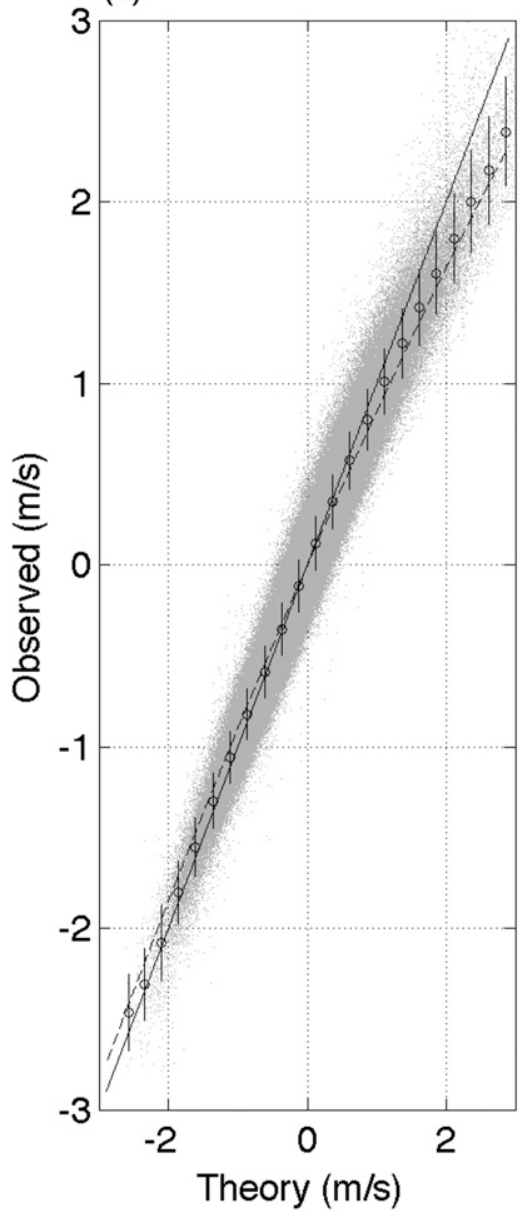

(b)

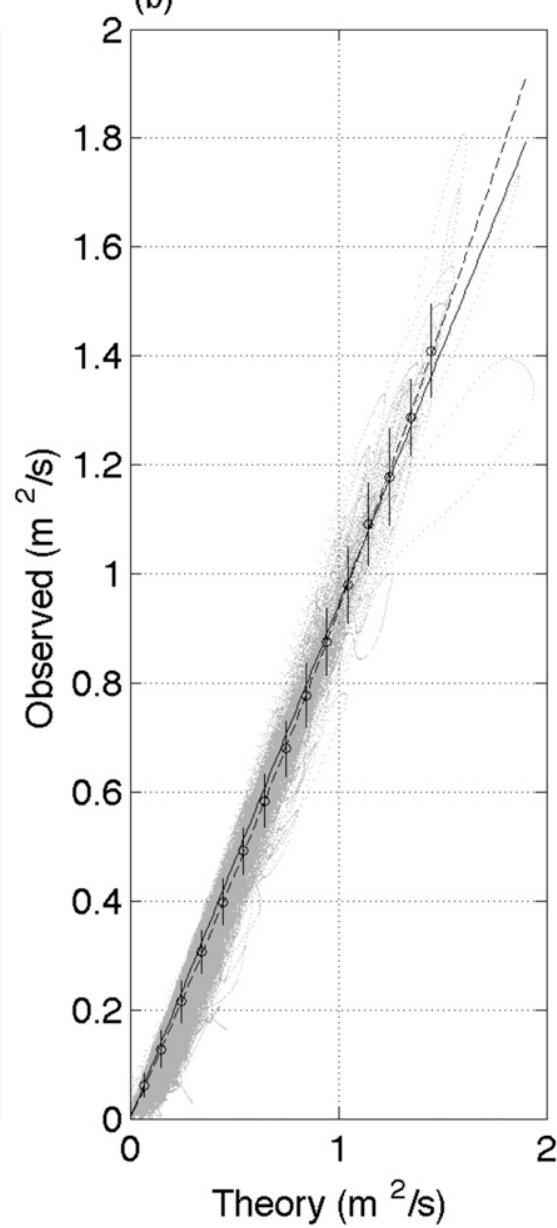

(c)

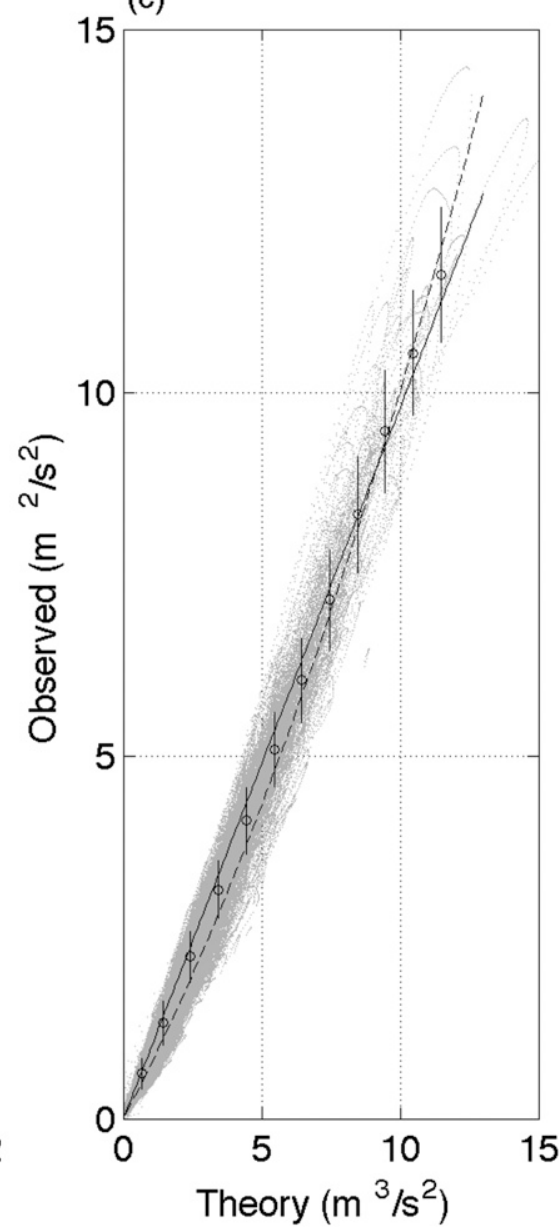

FIG. 7. Comparison of observed P2.5 wave velocities and wave properties to linear, shallow water theory with quadratic fits of data to theory shown to illustrate wave height-dependent deviations from linear theory. (a) Instantaneous velocities: raw (dots), bin averaged (open circles with vertical lines marking standard deviations for each bin), 1:1 agreement with theory (dashed line), and quadratic fit to binned data (solid line). (b),(c) As in (a), but for wave transport and radiation stresses, respectively.

problematic. Instead, the velocities can be described in $\sigma$ coordinates, where

$$
\sigma=\frac{z}{h+\eta}
$$

One approach to computing velocity fields under large amplitude waves is to recast linear theory in $\sigma$ coordinates simply by replacing $z / h$ with $\sigma$ (see Gudmestad and O'Connor 1986). The form these take for wave spectra, and written in terms of the rms velocities, are given in the appendix. Comparison of these vertical structure functions, (A11), with a sample of observed profiles taken at P2 (Fig. 10), shows that the structure of $w$ matches stretched linear theory, whereas $u$ is more strongly sheared near the surface than predicted. Nonetheless, linear fits of computed $q_{w}$ and $S_{\mathrm{xx}}$ versus predictions at P2 based on linear theory cast in terms of $\eta_{w}$, that is, using the frequency-dependent vertical structure, are quite good, with slopes of $0.88\left(q_{w}\right)$ and $0.93\left(S_{\mathrm{xx}}\right)$ for $\mathrm{P} 1$ and $0.90\left(q_{w}\right)$ and $0.98\left(S_{\mathrm{xx}}\right)$ for P2.

The degree to which shoaling of waves on the Moorea forereef conforms to simple theory can be assessed by computing the fluxes at offshore and onshore stations and then examining the shoreward wave energy flux, as shown in Fig. 11a for stations P1, P2, and P2.5. The inferred dissipation rates (from $\mathrm{P} 1$ to $\mathrm{P} 2$ and from $\mathrm{P} 1$ to P2.5) shown in Figs. 11b and 11c can be computed with reasonable accuracy $\left(r^{2}=0.65, r^{2}=0.44\right)$ using the standard representation of bottom friction (e.g., Jonsson 1980),

$$
\langle\varepsilon\rangle=\frac{2}{3 \pi} f_{w}\left|u_{b}\right|^{3}
$$

based on the observed near-bottom velocities $u_{b}$ at P1, $\mathrm{P} 2$, and $\mathrm{P} 2.5$, along with fitted wave friction factors 


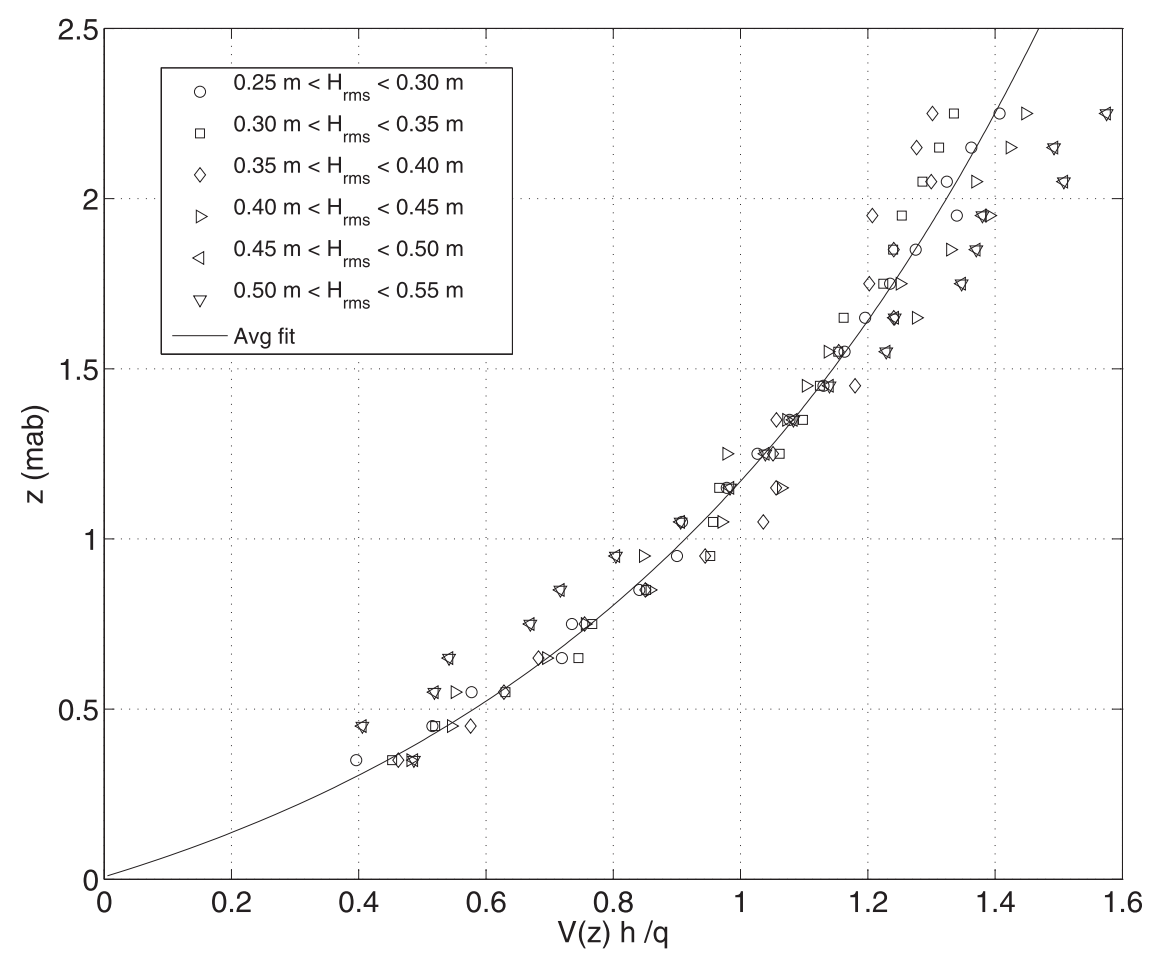

FIG. 8. Profiles of the alongshore velocity on the forereef at P2.5 normalized by the total across-reef transport. Solid line is average of all conditions; symbols indicate profiles bin averaged by the different wave conditions in the record.

$f_{w}=0.29 \pm 0.01$ (for the region between $\mathrm{P} 1$ and $\mathrm{P} 2$ ) and $f_{w}=0.21 \pm 0.01$ (from P1 to P2.5). These friction factors are well within the range of what has been found in past studies of waves on reefs, for example, $f_{w} \approx 0.1 \rightarrow 0.4$ (Nelson 1996; Lowe et al. 2005; Bandet 2009). As an aside, given that reflection coefficients for this geometry are likely to be $10 \%$ at most (cf. Yao et al. 2013), reflection would only have a $1 \%$ effect on energy fluxes.

The effect on setup of energy dissipation during shoaling is moderated by the 0.4 power law given by (5). In our case, the observed $25 \%$ reduction in wave energy flux at the edge of the surfzone (P2.5), relative to offshore (P1), means that the setup would have been $10 \%$ less than what it would have been had the wave energy flux not been reduced. In the setup calculations discussed below, we have assumed that the wave energy flux arriving at the surfzone was always $75 \%$ of the computed flux at P1.

Breaking and interaction of the borelike broken waves with the shallow reef crest dramatically attenuates the wave field on the backreef (Fig. 12a). At the first station inshore of the surfzone and reef crest (P3), the velocities were primarily directed shoreward and still strongly correlated with free surface variations (Fig. 12). However, the relationship between free surface elevation and velocity is not as clear as on the forereef with $u \approx 0.79 \sqrt{g / h} \eta$
(Fig. 13), albeit with considerably larger scatter, possibly reflecting the highly turbulent nature of the flow immediately inshore of the reef crest. Low-frequency variation's elevations seem to correspond to the residual groupiness of the gravity waves. Most importantly, the wave transport is quite small and essentially all of the cross-reef transport is carried by the mean Eulerian flow.

\section{Mean flows over the reef}

A summary of wave and mean flow properties at the shallowest forereef station (P2.5) is shown in Fig. 14. Short-term variations in wave-averaged variables were removed by averaging all variables over each 1024-s wave data burst. As seen in the short burst shown in Fig. 6, the cross-reef flow is almost entirely carried by wave transport, although tidal variations in the mean Eulerian flow, especially near the end of the record are apparent. In contrast, the along reef flow is entirely Eulerian, reflecting the fact that the direction of wave propagation is nearly perpendicular to the reef crest at the edge of the surfzone.

The varying importance of the wave transport with cross-reef position can be seen by comparing flows at the forereef station P2 (Fig. 15) and backreef station P3 
(a)

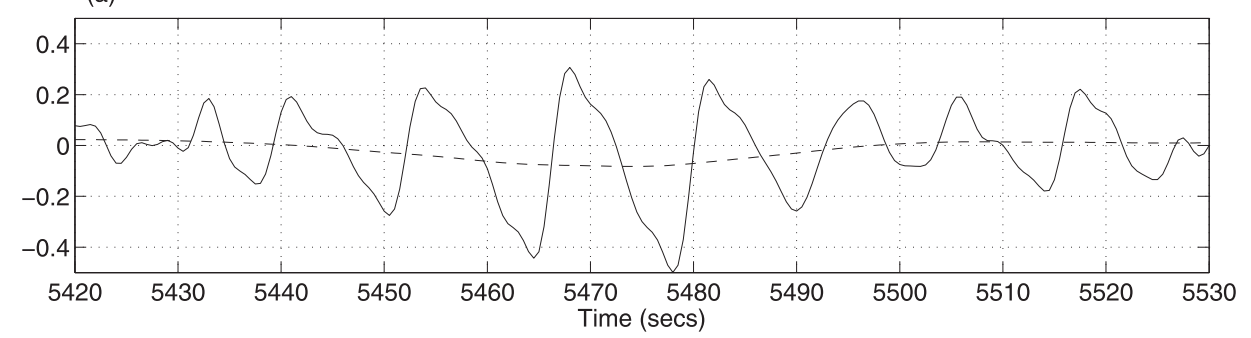

(b)

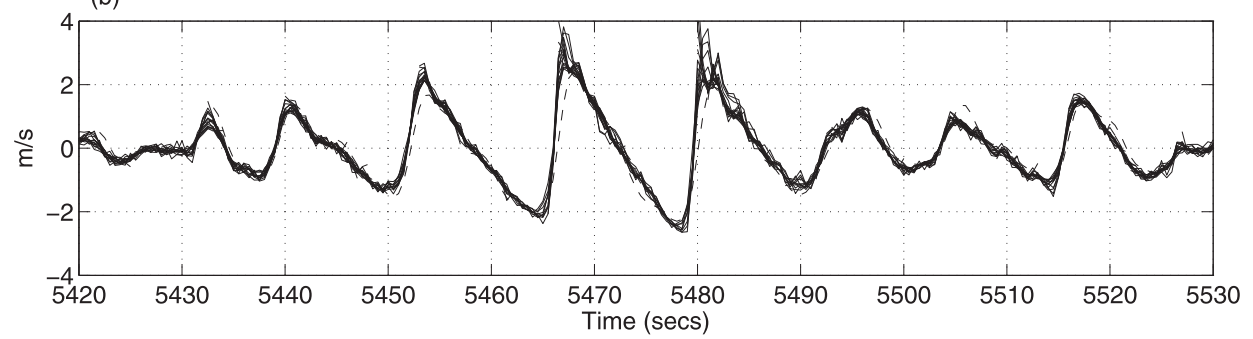

(c)

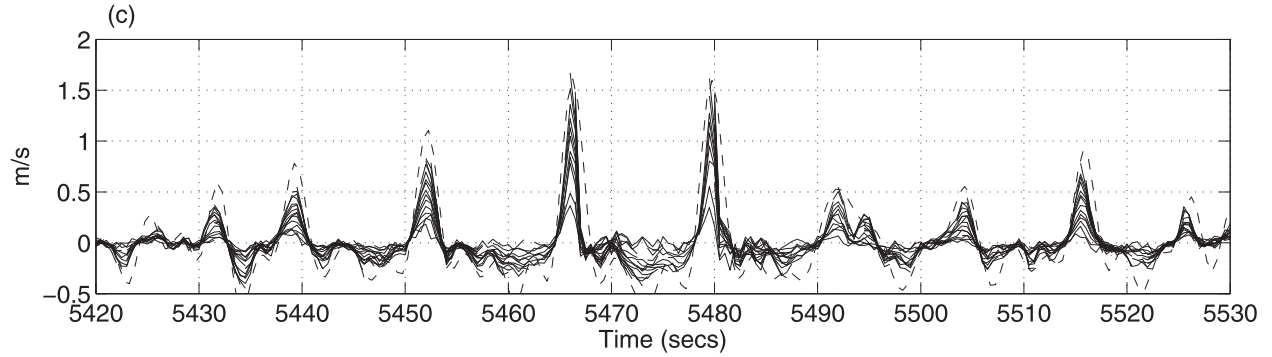

FIG. 9. Example 110-s wave burst data at forereef station P2: (a) high-pass (dashed line) and low-passfiltered free surface elevation (solid line), both normalized by local mean depth. (b) Measured high-passfiltered cross-shore velocities at all depths (dashed line) and as predicted using linear, shallow water theory (solid lines). (c) Measured high-pass-filtered vertical velocities at all depths (dashed line) and the vertical velocity at the free surface as predicted using linear, shallow water theory (solid lines).

(Fig. 16) to those at P2.5 (Fig. 14). Mean Eulerian flows are important both offshore and inshore of P2.5, demonstrating clearly the fact that in wave-driven flows over reefs, there is an interchange between wave transport and mean flow transport that occurs both offshore of the surfzone as a result of wave shoaling as well as within the surfzone as a result of breaking.

Overall, the temporal variability in mean transports at all cross-reef stations, as well as the reef pass (Fig. 17a), is quite similar and closely matches variability in the incident wave forcing. This similarity is perhaps surprising, given the complex topography and roughness of the backreef, and the fact that at any distance from the reef crest, the open area normal to the flow can vary substantially with distance from the reef crest. For example, the area between the reef crest and backreef stations $\mathrm{P} 3$ and $\mathrm{P} 4$ is relatively open, whereas the area between P4 and P5 has large areas of coral bommies that occupy a large fraction of the water column. Thus we made linear fits $q_{i}=a_{i} q_{2.5}+q_{0}^{i}$ of the transports at all stations to the transport at $\mathrm{P} 2.5$, the results of which are shown in Table 2. Interestingly, the transports at $\mathrm{P} 2$ and AP had no offset, confirming the continuity of the flow over the reef from offshore and back out the reef pass (as seen in Hench et al. 2008). In contrast, the backreef stations appear to show a divergent flow that is strongest at P7 and is near zero at the reef crest along this cross-reef transect. Nonetheless using this linear fit, the time variability of flow at all stations is essentially identical.

The flow time series in Fig. 17b show semidiurnal tidal variability. This flow variability is primarily not directly due to the tides. Rather it reflects the fact that, because the mean depth of water over the reef crest is nearly zero, small changes in depth over the reef crest because of the tide can weakly modulate the wave-driven flow. The variability in $q_{2.5}$ is $\pm 0.1 \mathrm{~m}^{2} \mathrm{~s}^{-1}$. Given an approximate reef length of $2300 \mathrm{~m}$ feeding the flow out Avaroa pass (Hench et al. 2008), this implies a tidal variation of flow of $\pm 230 \mathrm{~m}^{3} \mathrm{~s}^{-1}$. In contrast, the diurnal tidal 
(a) $02 / 08 / 0920: 54$

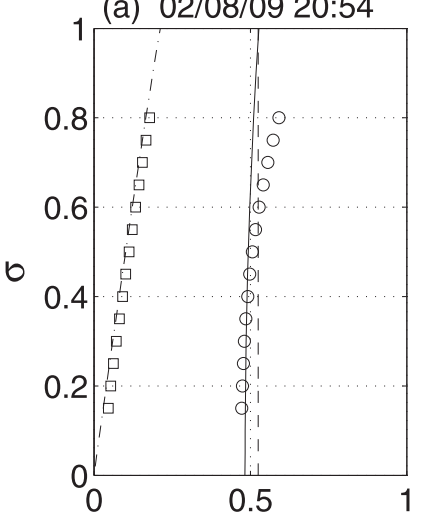

(d) $02 / 15 / 09$ 08:42

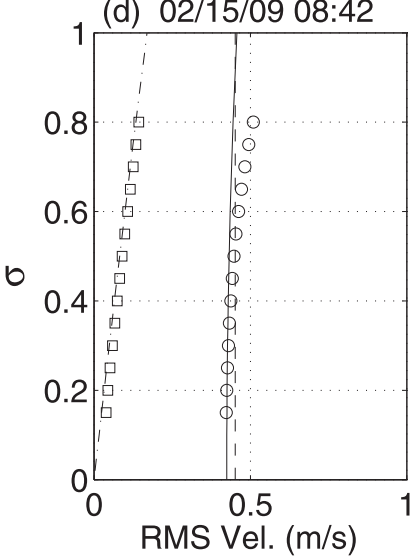

(b) $02 / 11 / 0900: 50$

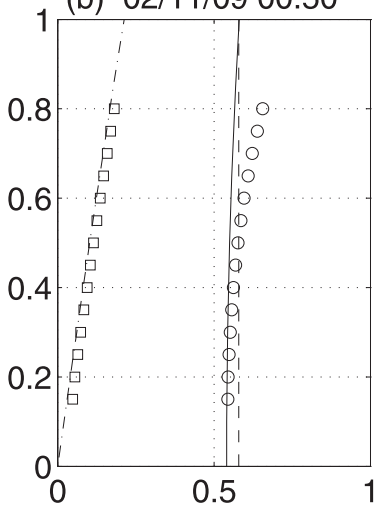

(e) $02 / 17 / 0912: 38$

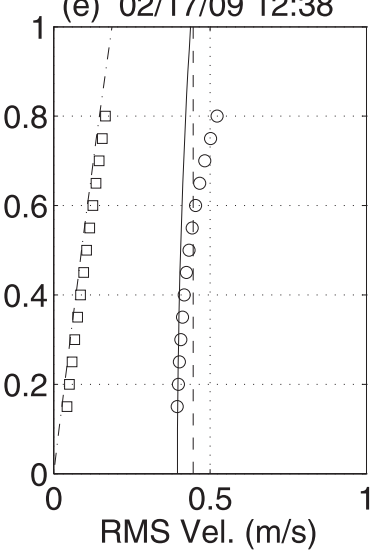

(c) $02 / 13 / 09$ 04:46
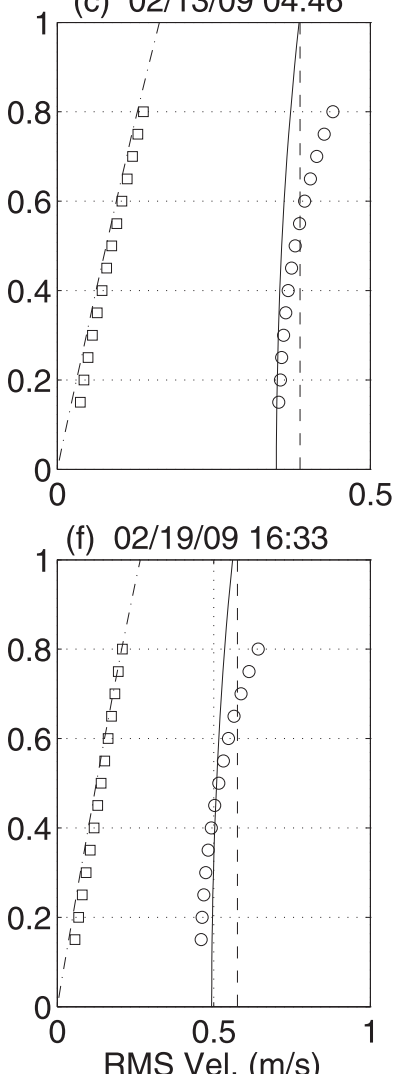

FIG. 10. Examples of vertical structure of observed rms cross reef velocities at forereef station P2 (open circles), rms vertical velocities (open squares), and velocity predictions made using linear theory expressed in $\sigma$ coordinates [vertical (dash-dotted line) and horizontal (dashed line).] Predicted depthaveraged rms cross-reef velocities are also shown (solid line).

variation in elevation is $\sim 11 \mathrm{~cm}$ (Herdman 2012). Given that the surface area of Paopao Bay is $3.5 \times 10^{6} \mathrm{~m}^{2}$, this would imply a tidal flow of $\pm 56 \mathrm{~m}^{3} \mathrm{~s}^{-1}$ - that is, the tidal flow is only about $25 \%$ the tidal variation in cross-reef flow that we observe. As shown below (Fig. 17b), the free surface setup is not tidally modulated, implying that the tidal variation in flow must be due to variations in frictional drag of flow over the shallow reef crest.

\section{Setup of the water surface and drag}

A key outcome of wave shoaling and breaking on the forereef is the setup of the free surface near the reef crest since it is this setup that drives the mean flow through the system. In this section, we will present an approach for determining this setup from the observations and then relate it to the observed setup to the incident wave energy flux, notably aiming to test the validity of the prediction represented by (5). To compute the incident wave energy flux $F_{w}$, we included the effects of dissipation by assuming that the energy flux arriving at the surfzone is $75 \%$ of that at $\mathrm{P} 1$ but neglected the effects of directional variation of the incident wave field. A detailed examination of the February 2009 data showed that a fit of (5) to the observed setup using the flux at P1 not corrected for direction was statistically indistinguishable from one based on the shoreward component of the flux at P2.5, with the only differences being in slightly different (ca. $3 \%$ ) values of the constants $A$ and $B$. We applied this same correction to the Oli data, assuming that there was little dissipation between the 20- and 6-m isobaths.

The low-frequency variation of the free surface elevation at two stations, P1 (forereef) and P3 (backreef) is shown in Fig. 18a, where the effect of wave forcing is seen as a modification of tidal variations in depth. However, reflecting the fact that tides in the backreef and lagoon are primarily a co-oscillation with the offshore tide (Hench et al. 2008), the wave setup can be seen by taking the difference of these two signals 
(a)

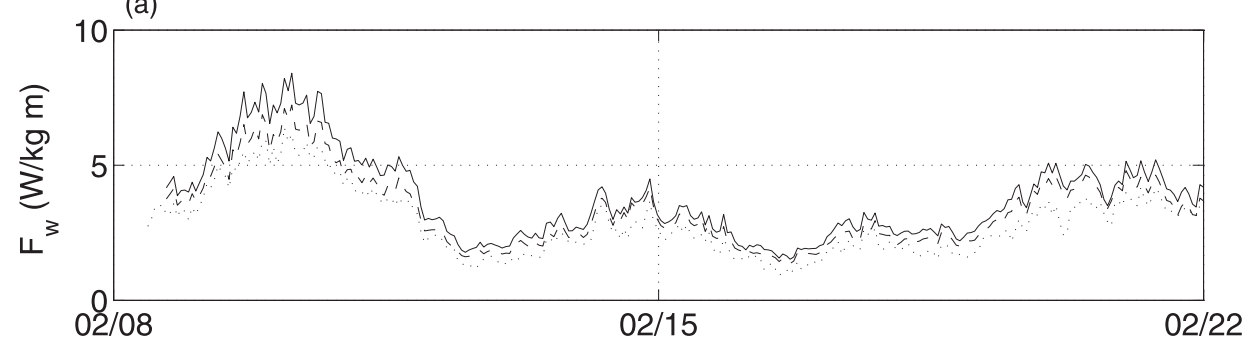

(b)

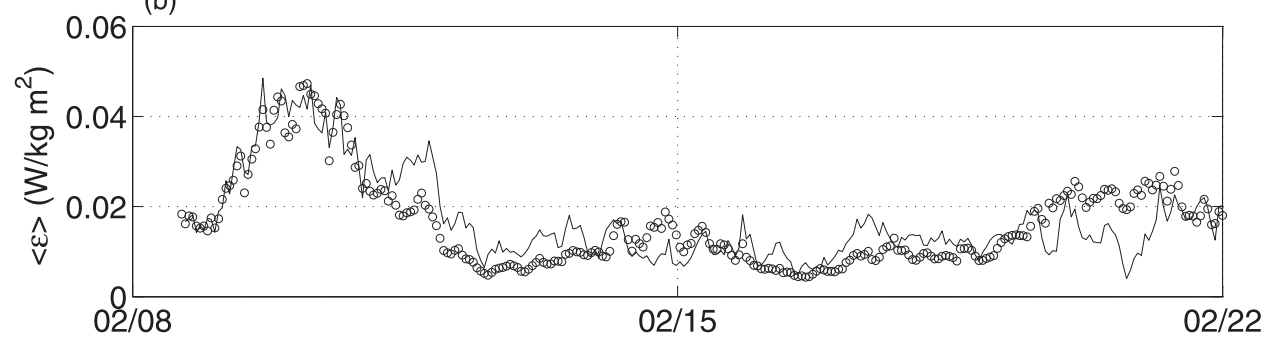

(c)

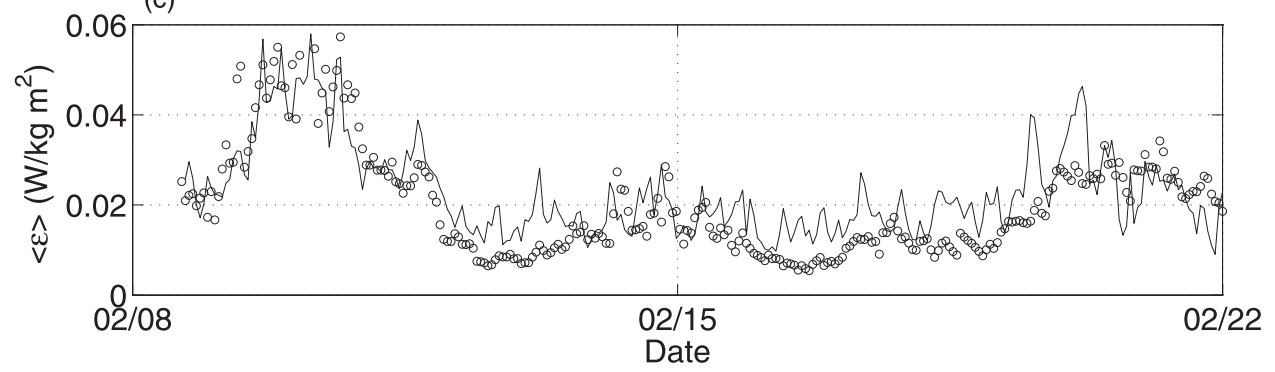

FIG. 11. (a) Shore-normal wave energy fluxes at P1 (dashed line), P2 (solid line), and P2.5 (dotted line). (b) Wave energy dissipation between station P1 and P2: observed (solid line) and modeled (open circles).

(c) Wave energy dissipation between station P1 and P2.5: observed (solid line) and modeled (open circles).

(Fig. 18b). However, as we explain below, this difference includes the setup resulting from the mean wave conditions during the period of observation. Thus, to determine this mean wave setup from the data, consideration must be given to the dynamics of the flow through the backreef.

To start, the pressure time series measured by a given sensor can be decomposed as follows:

$$
\frac{P_{i}}{\gamma}=h_{i}=h_{i}^{0}+\langle\eta\rangle_{i}^{w}+\langle\eta\rangle_{i}^{t}+\langle\eta\rangle_{i}^{\mathrm{nt}}+\tilde{\eta}_{i}
$$

where the overall measured pressure (expressed as a depth) is written as the sum of the mean depth of the pressure sensor $h_{i}^{0}$ the wave-induced mean sea level change $\langle\eta\rangle_{i}^{w}$, the tidal sea level variation $\langle\eta\rangle_{i}^{t}$, a nontidal component (e.g., low-frequency sea level variations) $\langle\eta\rangle_{i}^{\mathrm{nt}}$, and the instantaneous apparent wave perturbation to the depth $\tilde{\eta}_{i}$. Low-pass filtering the measured pressure to remove the waves gives

$$
\left\langle h_{i}\right\rangle=h_{i}^{0}+\langle\eta\rangle_{i}^{w}+\langle\eta\rangle_{i}^{t}+\langle\eta\rangle_{i}^{\mathrm{nt}} .
$$

Averaging (11) over the whole record gives

$$
\overline{\left\langle h_{i}\right\rangle}=h_{i}^{0}+\overline{\langle\eta\rangle_{i}^{w}}+\overline{\langle\eta\rangle_{i}^{t}} \simeq h_{i}^{0}+\overline{\langle\eta\rangle_{i}^{w}}+\overline{\langle\eta\rangle_{i}^{t}}+\overline{\langle\eta\rangle_{i}^{\mathrm{nt}}} .
$$

Here we have assumed that the record is long enough for the mean tidal sea surface deviation to be zero. Thus,

$$
\left\langle h_{i}\right\rangle-\overline{\left\langle h_{i}\right\rangle}=\langle\eta\rangle_{i}^{w}+\langle\eta\rangle_{i}^{t}-\overline{\langle\eta\rangle_{i}^{w}}+\langle\eta\rangle_{i}^{\mathrm{nt}}-\overline{\langle\eta\rangle_{i}^{\mathrm{nt}}}
$$

and so a single record cannot be used to directly infer the wave-induced setup. Moreover, the mean flow through the backreef that is not connected to the wave forcing should require a spatially variable but time-invariant setup; this will be necessarily removed by this averaging as well.

If we suppose that the tidal and nontidal elevations are approximately the same at all the measurement stations, the quantity 

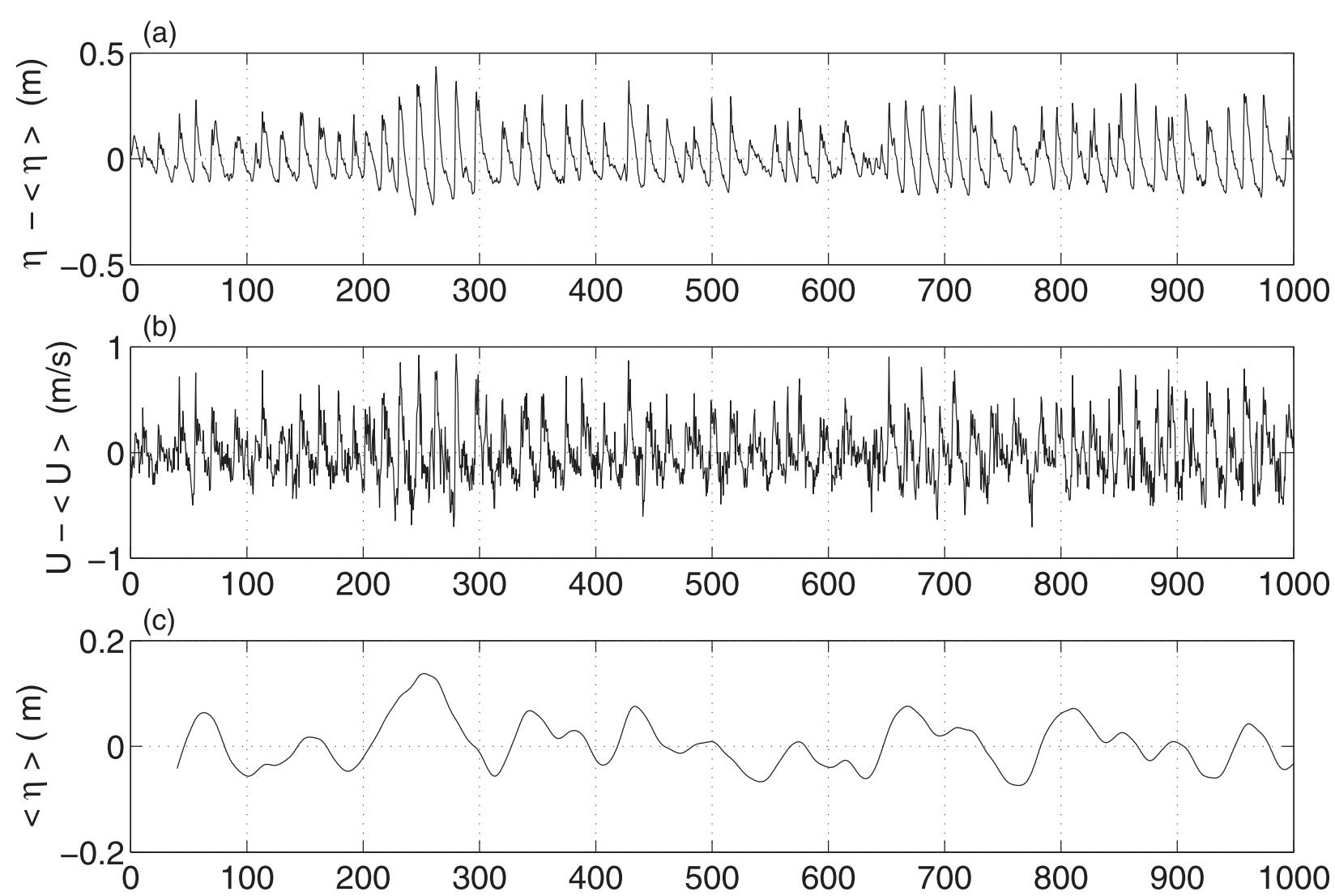

(d)

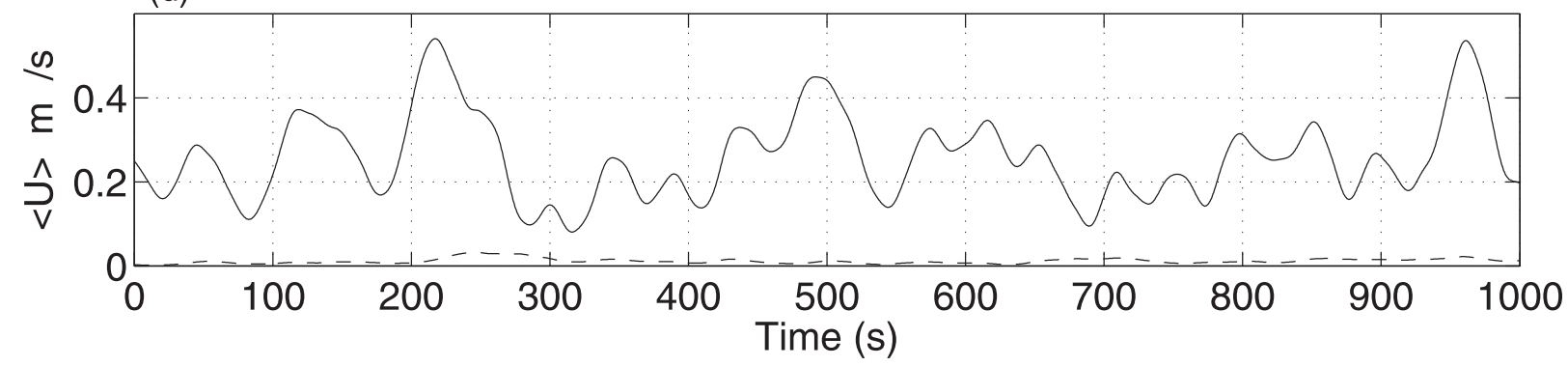

FIG. 12. Example 1024-s wave burst of data at backreef station P3: (a) high-pass-filtered free surface elevation; (b) high-pass-filtered (wave) cross-shore velocity; (c) low-pass-filtered free surface elevation; and (d) low-pass-filtered (wave) cross-shore velocity (dashed line) and alongshore velocity (solid line).

$$
\begin{aligned}
\Delta_{i j} & =\left(\left\langle h_{i}\right\rangle-\overline{\left\langle h_{i}\right\rangle}\right)-\left(\left\langle h_{j}\right\rangle-\overline{\left\langle h_{j}\right\rangle}\right) \\
& =\langle\eta\rangle_{i}^{w}-\overline{\langle\eta\rangle_{i}^{w}}-\langle\eta\rangle_{j}^{w}+\overline{\langle\eta\rangle_{j}^{w}},
\end{aligned}
$$

that is, the difference in low-frequency water level variations between stations $i$ and $j$, can be used to define wave-induced changes in water level. The extent to which this is true is reflected in the extent to which there is tidal variability in $\Delta_{i 1}$, although some tidal variation may remain because tides modulate the depth over the reef crest and hence, to some extent the wave setup. Note that $\overline{\langle\eta\rangle_{i}^{w}}$ is the mean wave-induced change in water level over the measurement period. Ideally, the most offshore station could be chosen sufficiently far offshore that wave-induced changes in water level would be negligible (cf., Vetter et al. 2010), in which case

$$
\Delta_{i 1} \simeq\langle\eta\rangle_{i}^{w}-\overline{\langle\eta\rangle_{i}^{w}}
$$

However, in the present case, station P1 (furthest offshore) might be expected to have a set down $\approx 1 \mathrm{~cm}$ for the largest waves (per Longuet-Higgins and Stewart 


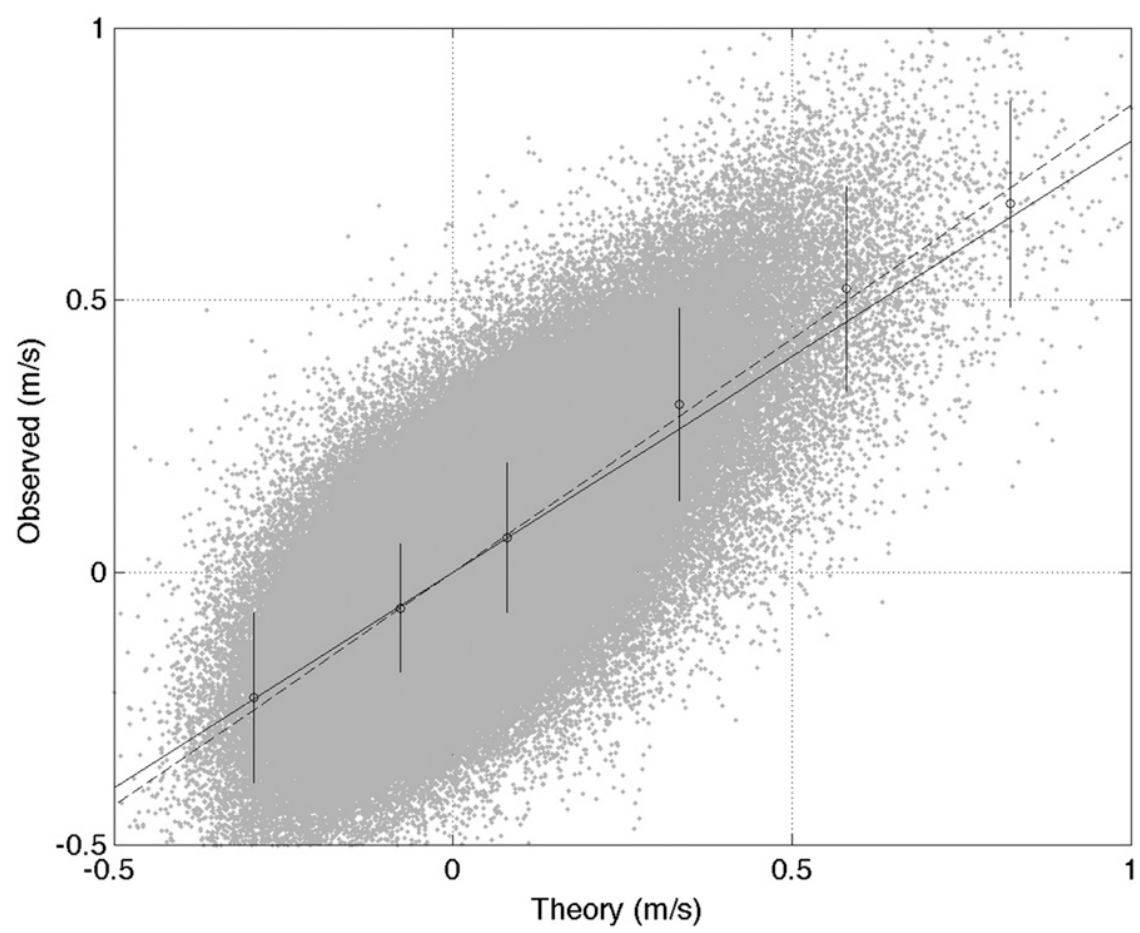

FIG. 13. Comparison between observed and predicted cross-reef velocities at backreef station P3: raw data (dots); standard deviations in each velocity bin (vertical lines with open circles); linear fit to binned data (dashed line with slope $=0.79$, ); and linear fit to all data (solid line with slope $=0.86$ ).

1964), implying that setup deduced from (15) might be biased slightly downward. However, the difference in depths across the surfzone, in our case $\Delta_{2.53}$, does correspond to the setup predicted by (5), albeit with the caveat detailed below. For the present data, we found that $\Delta_{2.53}=1.12 \pm 0.002 \Delta_{13}$. Nonetheless, it is the setup relative to offshore that provides the barotropic pressure gradient that drives the mean flow through the reef.

Now suppose that we can fit the data as

$$
\langle\eta\rangle_{i}^{w}=A F_{w}^{\alpha}+B
$$

For example, (5) gives $\alpha=0.4$. Thus,

$$
\Delta_{i 1}=A_{i}\left(F_{w}^{\alpha}-\overline{F_{w}^{\alpha}}\right)
$$

implying that the constant part of the setup $B_{i}$ cannot be determined from pressure measurements alone, although the variability of setup with the wave parameters $A_{i}$, and $\alpha$ can be found by least squares fitting to the observations.

Considering the flow half way between two stations, $i$ and $i+1$, and assuming a pressure-friction balance, (1) can be approximated by

$$
\begin{aligned}
C_{D}^{i, i+1} \frac{1}{2}\left(\frac{q_{i}^{2}}{h_{i}^{3}}+\frac{q_{i+1}^{2}}{h_{i+1}^{3}}\right) & \simeq-g \frac{\langle\eta\rangle_{i+1}^{w}-\langle\eta\rangle_{i}^{w}}{x_{i+1}-x_{i}} \\
& =-g \frac{\left(A_{i+1}-A_{i}\right) F_{w}^{\alpha}+B_{i+1}-B_{i}}{x_{i+1}-x_{i}} .
\end{aligned}
$$

Note that in (18), three quantities are unknown, $C_{D}^{i, i+1}$, $B_{i}$, and $B_{i+1}$. Moreover, (18) can be rearranged to take the form $Y=a X+b$, with

$$
\begin{aligned}
Y & =\left(\frac{q_{i}^{2}}{h_{i}^{3}}+\frac{q_{i+1}^{2}}{h_{i+1}^{3}}\right) \\
X & =F_{w}^{\alpha} \\
a & =-\left(\frac{2 g}{C_{D}^{i, i+1}}\right)\left(\frac{A_{i+1}-A_{i}}{x_{i+1}-x_{i}}\right) \\
b & =\left(\frac{2 g}{C_{D}^{i, i+1}}\right)\left(\frac{B_{i+1}-B_{i}}{x_{i+1}-x_{i}}\right) .
\end{aligned}
$$

Thus by fitting this line with $a$ and $b, C_{D}^{i, i+1}$ and $B_{i+1}-B_{i}$ can be found. Ideally, at the most shoreward station $(i=M) B_{M} \approx 0$. In this way, one can proceed by first 
(a)

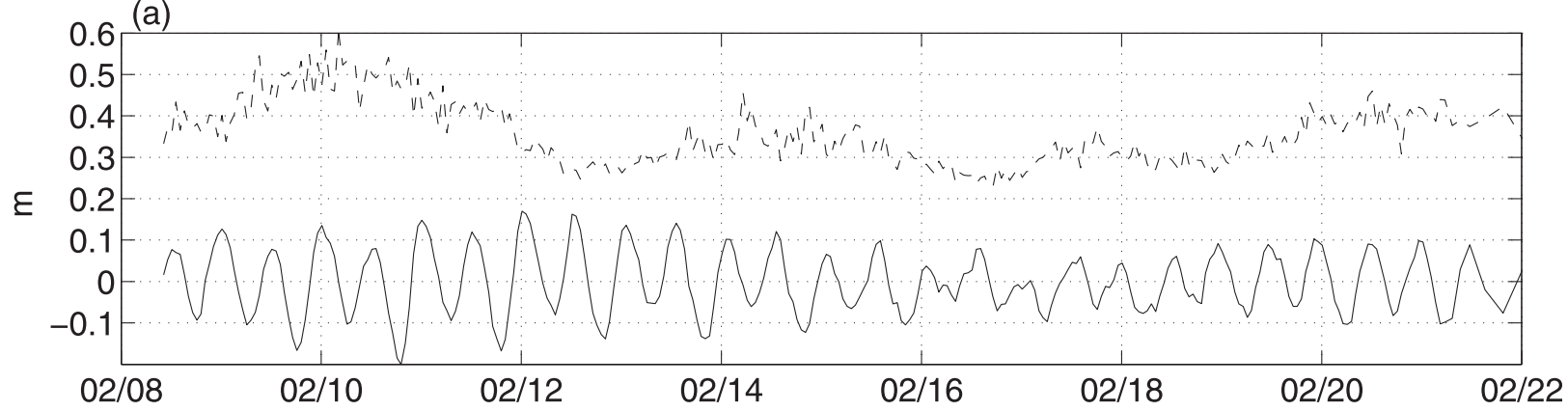

(b)

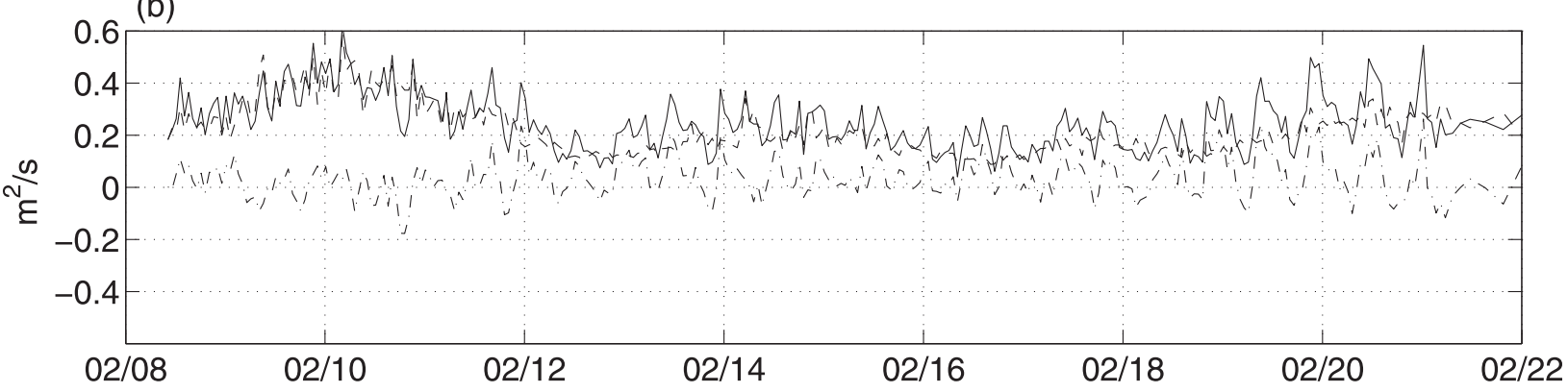

(c)

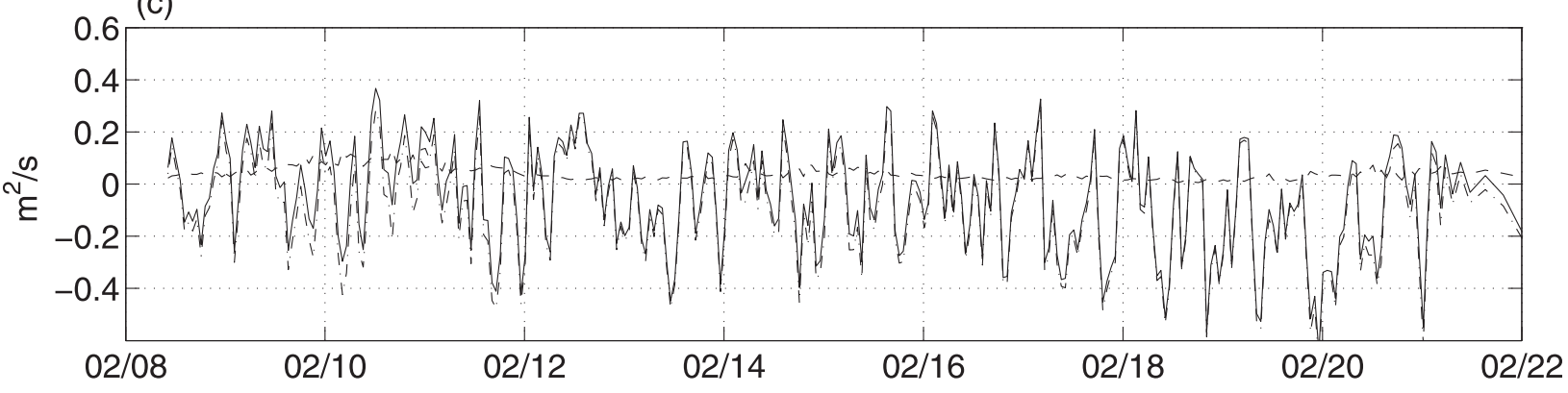

FIG. 14. Summary of forcing and flows at P2.5: (a) wave height $H_{\text {rms }}$ (dash-dotted line) and tidal height variation (solid line); and (b),(c) cross- and along-reef transports, respectively: total (dashed line), Eulerian (dash-dotted line), and wave (solid line).

fitting the flow data between $i=M-1$ and $i=M$ to find the best-fit value of $C_{D}^{i, i+1}$ and $B_{M-1}$. With $B_{M-1}$ known, one can next compute $M-1$ and so forth. In our case, wave-averaged water level at the most shoreward station (P7) showed a response to the wave forcing. Thus, as an approximation, we assumed that the ratio of maximum setup to minimum setup should be the same as the ratio of the squares of the maximum and minimum flows.

The results of this fitting are shown in Table 3. The extent to which the pressure balance is valid for the region between P4 and P7 is shown in Fig. 19, comparing inferred pressure and shear stress gradients. Note that, since we use the total flows and not just the wave driven part in (18), the constant setups $B_{i}$ include the mean setups owing to drag on the constant part of the flow. However, given that the overall setup driving the flow through the backreef is determined by what happens in the surf zone, this points out the fact that the flow driven by the wave setup also depends on whatever other flows are present, for example, tides or other low-frequency flows, since given a quadratic drag law, these increase the drag on the wave-driven portion of the flow.

Least squares fitting to stations $\mathrm{P} 3$ and $\mathrm{P} 4$ gave identical fits, that is, $A_{3} \simeq A_{4}$, so that the variable part of the pressure gradient was essentially zero. However in this region the radiation stress gradient appears to be nonnegligible, so that the momentum balance must be approximated as

$$
C_{D}^{3,4} \frac{q^{2}}{h^{3}} \simeq-\frac{1}{\rho} \frac{d S_{\mathrm{xx}}}{d x} \simeq-\frac{3 g}{2} \frac{d}{d x}\left(\overline{\eta^{2}}\right)
$$

where we have written the radiation stress in terms of the mean square free surface displacement in shallow water, $\overline{\left\langle\eta_{w}^{2}\right\rangle}$ [per (A5)]. The results of linear regression of the finite-difference version of are also included in Table 3. 
(a)

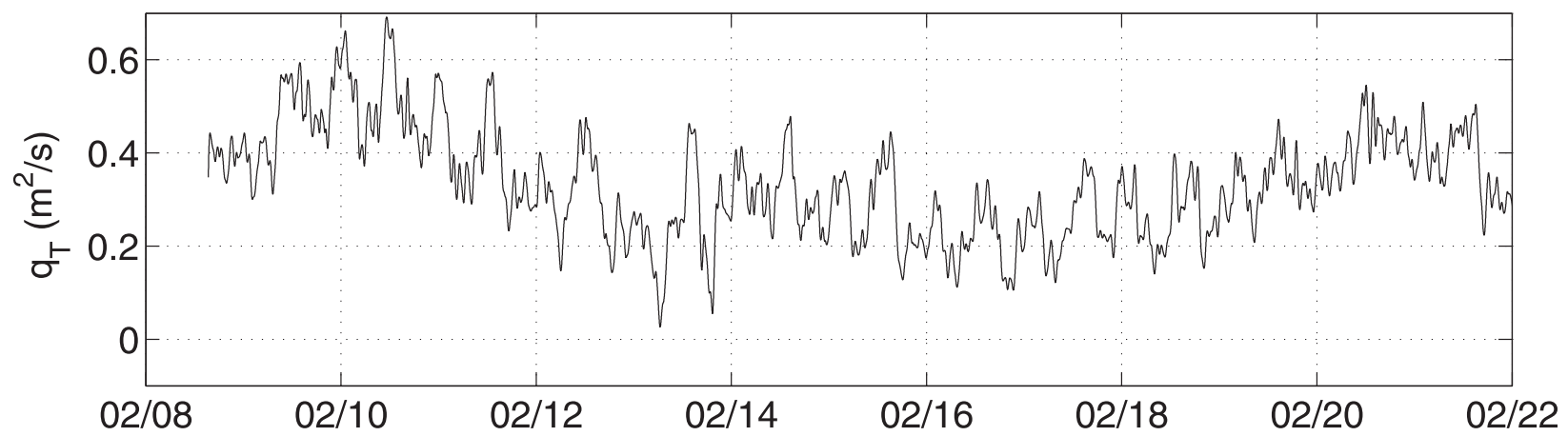

(b)

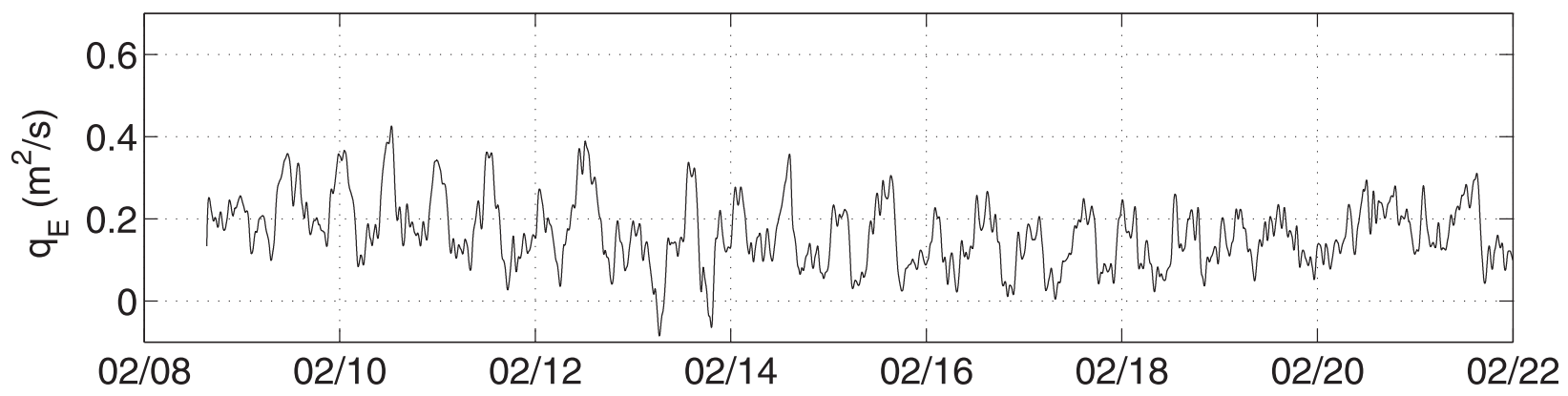

(c)

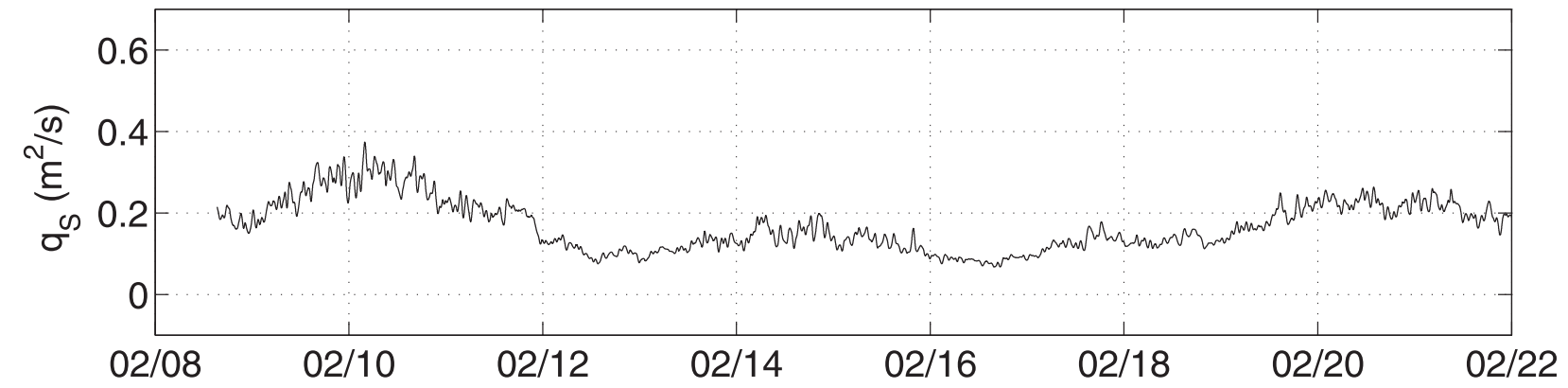

FIG. 15. Cross-reef transports at forereef station P2: (a) total transport; (b) Eulerian transport; and (c) wave transport.

The backreef station $\mathrm{P} 3$ is close to the reef crest so that it can be taken to reflect the setup at the end of the surfzone. From (5)

$$
A=\frac{3 \gamma^{2}}{8+3 \gamma^{2}} \frac{8^{2 / 5}}{\gamma^{4 / 5} g^{3 / 2}}
$$

thus, the fitting shown in Table 1 gives $A=0.154 \pm 0.003$ $\left(r^{2}=0.89\right)$ and $B=-0.117 \pm 0.004$ implying that $\gamma \simeq$ $0.95 \pm 0.03$ and $h_{r} \simeq 0.46 \pm 0.02 \mathrm{~m}$, the latter being a value that is comparable to the height of the reef ridge. Including the December 2008-February 2009 deployment, processed in the same way as was the February 2009 data, gives a nearly identical fit: $\gamma \simeq 0.98 \pm 0.01$ and that $h_{r} \simeq 0.46 \pm 0.01 \mathrm{~m}$. A comparison of the time variability of the observed and predicted setup indicates that the model is in excellent agreement with the observations (Fig. 20).

As a further test of the theoretical prediction for setup under a wider range of wave conditions, we made similar calculations on a more spatially limited datasets collected at forereef station F20 and backreef station P5 during February 2007 and between December 2009 and May 2010. The latter record includes waves and wave setup produced by Cyclone Oli, a tropical storm that produced significant wave heights as large as $5.6 \mathrm{~m}$, much larger than normally seen on the North shore of Moorea. For this set of calculations, the incident wave field was derived from directional wave spectra estimates assuming that the onshore energy flux at P1 and at the deeper station were the same. The setup was computed as described above except that, (i) reflecting the setup ratio 
(a)

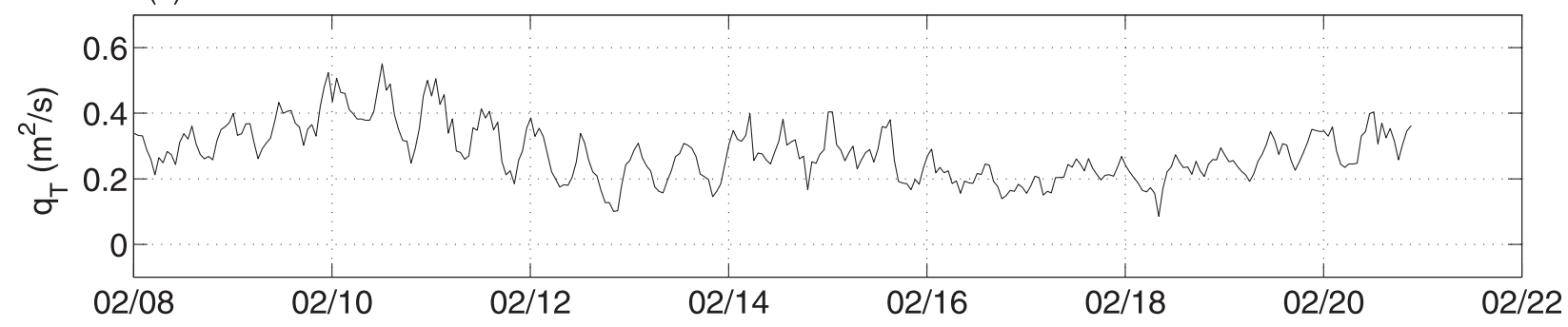

(b)

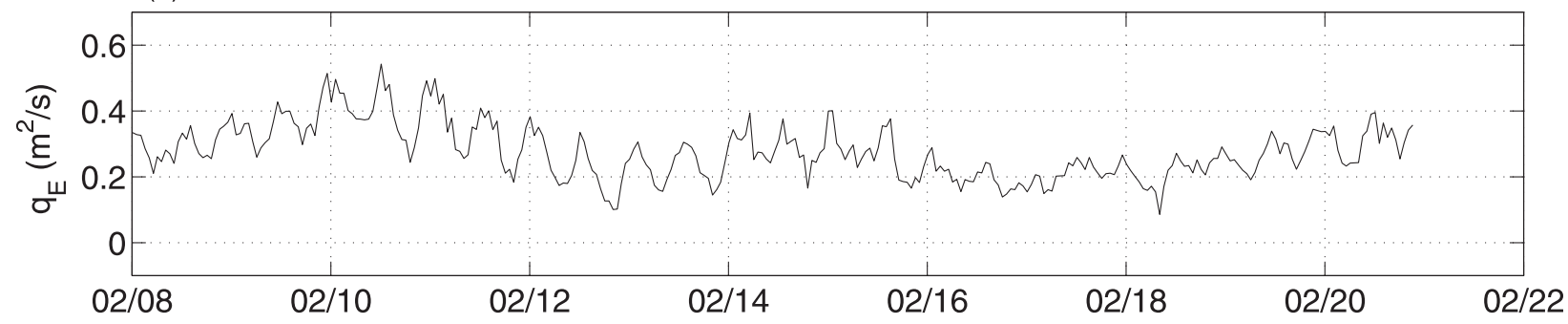

(c)

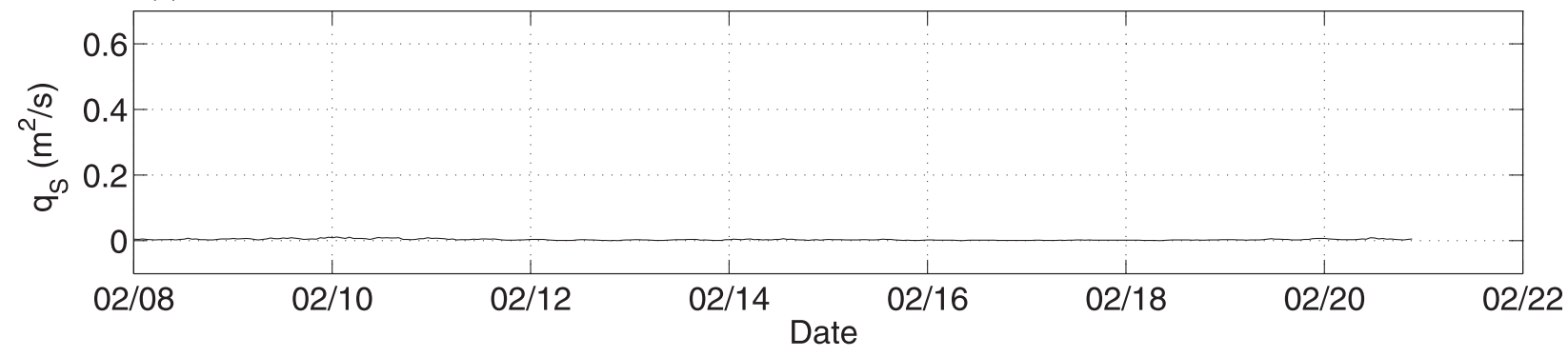

FIG. 16. As in Fig. 15, but for backreef station P3.

seen in the February 2009 data, the setup at P5 was multiplied by 1.25 ; and (ii) in the absence of suitable velocity data to use the pressure-friction balance described above, the static offset was chosen so that the setup for low wave forcing corresponded with the setups observed in February 2009 for the same forcing.

All of these datasets along with the fit derived for the December 2008-February 2009 data are shown in Fig. 21, where it is clear that overall, (5), evaluated using the constants derived from the December 2008February 2009 data, provides an excellent description $\left(r^{2}=0.86\right)$ of the setup response to the incident wave field for the Moorea reef complex.

The simple model is not truly predictive in that neither $\gamma$ nor $h_{r}$ could be specified in advance. For example, arguably $h_{r} \approx 0$, since the water depth over the reef crest is nearly zero and certainly varies tidally. Likewise, the value of $\gamma$ we determined is close to that found by Vetter et al. (2010) and is at the high end of the range of values Raubenheimer et al. (1996) would predict, 0.6-1.1 (computed for a bottom slope of $15 \%$, a depth of $3 \mathrm{~m}$, and average periods between 8 and 18s). The value we find for $\gamma$ is also larger than what would be given by the longwave limit of the Miche (1944) criterion for monochromatic waves, 0.88 . In any case, choosing a priori a single value of $\gamma$ for the forereef is difficult given the range of depths and periods despite the fact that, as seen in our data and as found by Vetter et al. (2010), a single value of $\gamma$ provides a reasonable prediction of the setup.

Besides setups, the analysis approach given above also yields estimates of the drag coefficients (also in Table 3 ). The drag coefficients so computed for the reef between stations 4 and 7 (ca. $7 \times 10^{-2}$ ) are similar to that found by Hench et al. (2008), who attributed the large observed drag to flow around the coral bommies found in that portion of the reef. In contrast the drag coefficient for the section near the reef crest (from P3 to P4) is somewhat smaller $\left(\mathrm{ca} .7 \times 10^{-3}\right.$ ) likely reflecting the relatively open nature of that region, with roughness largely associated with small coral heads on the bottom. This smaller drag coefficient is similar to what Reidenbach et al. (2006) found for flows over similar coral cover on a Red Sea reef. Like $\gamma\left(\right.$ and $\left.f_{w}\right)$, these drag coefficients are not predictions. As discussed by Nunes 
(a)

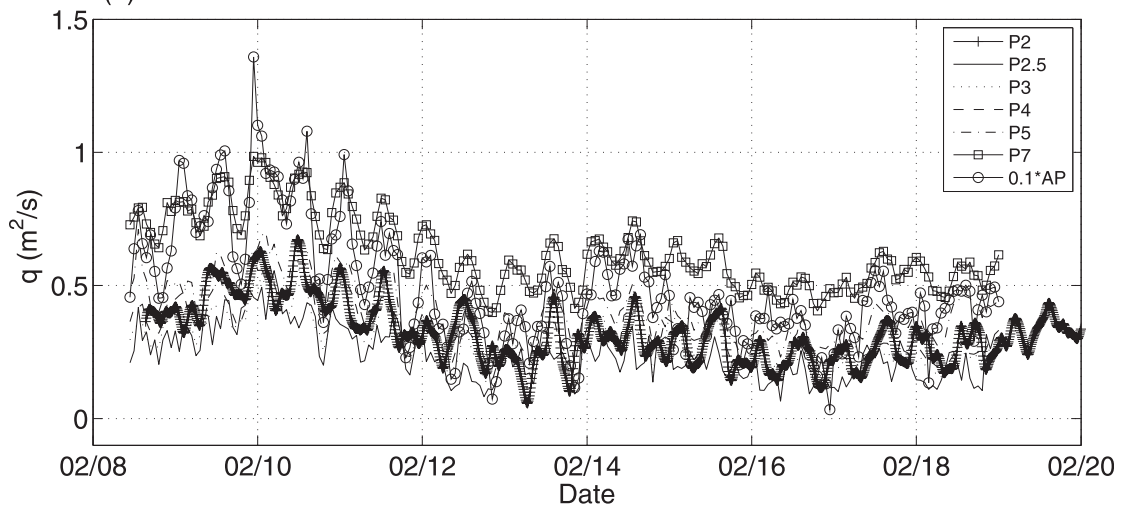

(b)

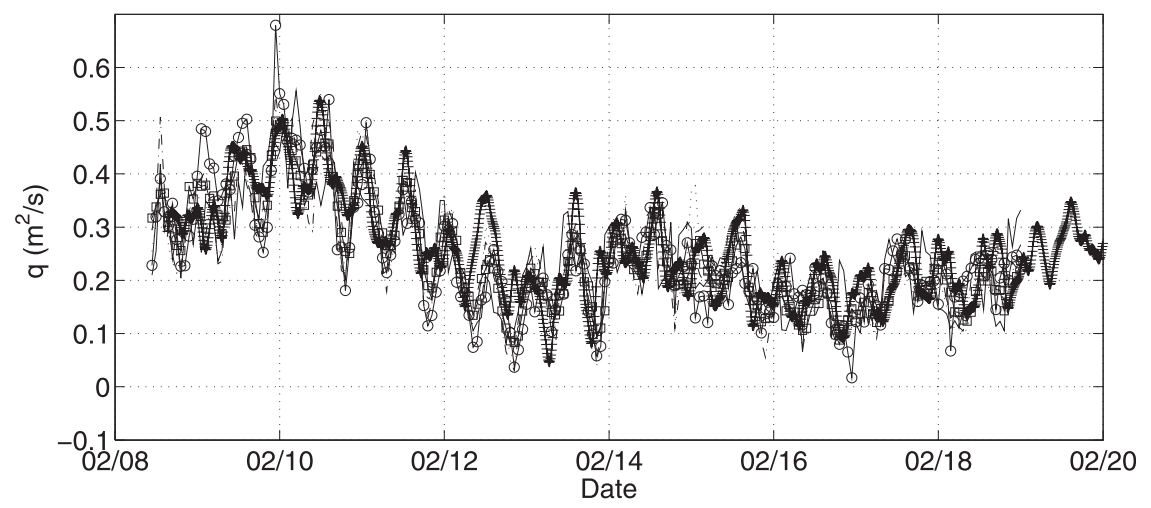

FIG. 17. (a) Wave-averaged total cross reef transports measured at P2, P2.5, P3, P4, P5, and P7 (see legend in inset) and Avaroa pass. (b) All transports linearly scaled to the transport at P2.5 (linear fits given in Table 1.)

and Pawlak (2008) and Bandet (2009), given the complexity of the flows involved, as well as the challenge of properly characterizing the surface geometry, the translation of observations of roughness (however characterized) into friction factors-drag coefficients as has been done for various simple rough surfaces remains an open question.

\section{Discussion and conclusions}

These measurements provide a relatively complete picture of waves and the mean flows they drive as they interact with a barrier reef and lagoon system. A number of features emerge. First, despite the steep slopes and large amplitudes and hence presumed nonlinearity of the shoaling waves on the forereef, linear wave theory provides remarkably good descriptions of the velocities and of the two integral quantities, radiation stress and wave transport, which are central to the theory of wave-averaged flows over the reef. As seen in studies of waves on low slope beaches, there is significant generation of infragravity waves in the surfzone, that is, the region inshore of breaking. This was also seen by Péquinet et al. (2011), who determined that while the infragravity wave spectrum may be important to runup, as on beaches, the energy transfer to the infragravity wave portion of the spectrum was much smaller than dissipation because of propagation over a rough reef. Presumably this would also be the case for the Moorea reef, where the apparent dissipation of incident wave energy reduced the wave energy flux at the edge of the surfzone by approximately $25 \%$ relative to offshore. Further analysis of this aspect of wave transformation on the forereef will be reported elsewhere.

TABLE 2. Flow scaling parameters (relative to P2.5).

\begin{tabular}{clc}
\hline Station & \multicolumn{1}{c}{$a$} & $q_{0}\left(\mathrm{~m}^{2} \mathrm{~s}^{-1}\right)$ \\
\hline P2 & 0.8 & 0 \\
P3 & 1.13 & 0.08 \\
P4 & 1 & 0.07 \\
P5 & 0.91 & 0.14 \\
P7 & 0.71 & 0.2 \\
AP & 0.05 & 0 \\
\hline
\end{tabular}


(a)

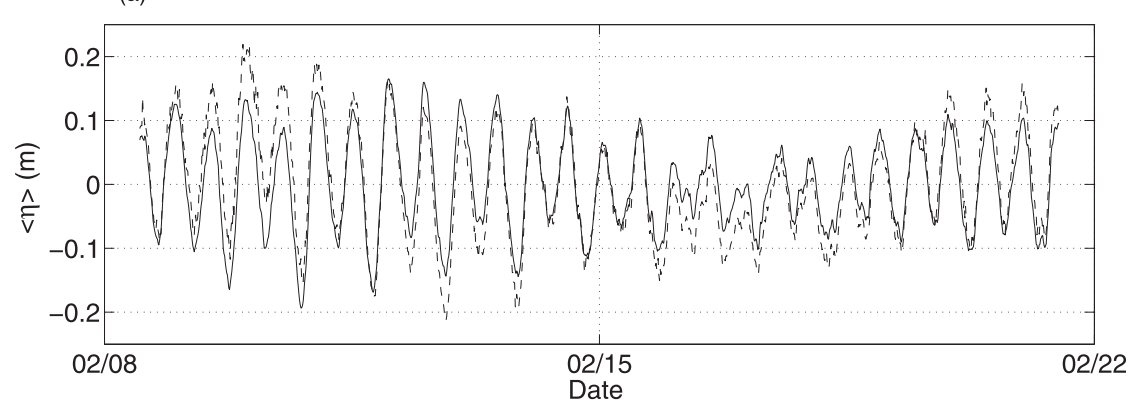

(b)

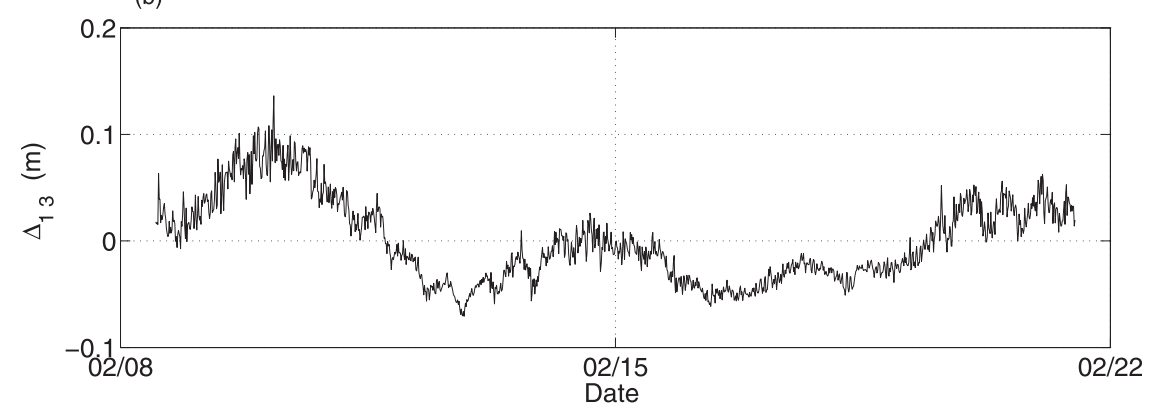

FIG. 18. (a) Low-pass-filtered free surface elevations with zero mean at stations P1 (dashed line) and P3 (solid line). (b) Difference between elevation changes at P1 and P3.

A more serious challenge for simple theory is the fact that the forereef geometry on many reefs is more complicated than what is shown our conceptual model for reefs (Fig. 1). For example, in Moorea and other reefs, there is often a shallow crest that nearly reaches mean water level, and separates the forereef and the backreef (see Fig. 2). Additionally, the forereef structure commonly is not planar, but rather consists of a series of ridges, known as spurs, separated by channels, known as grooves (Shinn 1963; Storlazzi et al. 2003). Given that these structures are generally much less than the wavelength of the incident waves, their effect is not amenable to perturbation approaches based on slowly varying geometry and their influences wave shoaling and breaking is largely unknown.

Second, the flows we observe show how fluid transport over the reef crest involves both wave transport and mean Eulerian flows, with the fraction of the transport carried by the waves being larger inshore than offshore as wave shoaling increases wave transport. In our measurements, at the station closest to surfzone, the crossreef transport was entirely associated with the waves. After the waves break, the wave transport was essentially negligible.

Finally, the strength of the cross-reef flow appears to be determined by a balance of bottom friction on the backreef with the barotropic pressure gradient associated with the set up created by the radiation stress gradient produced by wave breaking on the forereef (Symonds et al. 1995; Hearn 1999; Gourlay and Colleter 2005; Rosman and Hench 2011). In light of this, it is interesting that the flow just offshore of the wave break point shows nearly zero mean Eulerian cross-reef flow for all of the observed wave conditions. From a scaling standpoint, combining the setup predicted by (5) with a friction-pressure gradient balance on the backreef suggests that

$$
q_{T} \sim h_{r}^{3 / 2}\left(C_{D} L_{r}\right)^{-1 / 2} g^{4 / 5} F_{w}^{1 / 5} .
$$

In contrast, assuming shallow water waves, scaling for the wave transport offshore of wave breaking gives

$$
q_{s} \sim g^{1 / 6} h^{1 / 4} F_{w}^{1 / 2} .
$$

Because the dependence of the total transport and the wave transport on the wave energy flux $F_{w}$ is different,

TABLE 3. Model setup fitting parameters for backreef stations.

\begin{tabular}{crcccc}
\hline \hline Station & $x(\mathrm{~m})$ & $A$ & \multicolumn{1}{c}{$B(\mathrm{~m})$} & $\overline{\langle\eta\rangle_{w}}(\mathrm{~m})$ & $C_{D} \times 10^{3}$ \\
\hline P3 & 54 & $0.154 \pm 0.03$ & $-0.116 \pm 0.005$ & 0.12 & $6.2 \pm 0.2$ \\
P4 & 79 & $0.154 \pm 0.03$ & $-0.116 \pm 0.005$ & 0.12 & $76 \pm 1$ \\
P5 & 366 & $0.114 \pm 0.02$ & $-0.085 \pm 0.004$ & 0.10 & $66 \pm 1$ \\
P7 & 690 & $0.027 \pm 0.005$ & $-0.02 \pm 0.002$ & 0.04 & - \\
\hline
\end{tabular}




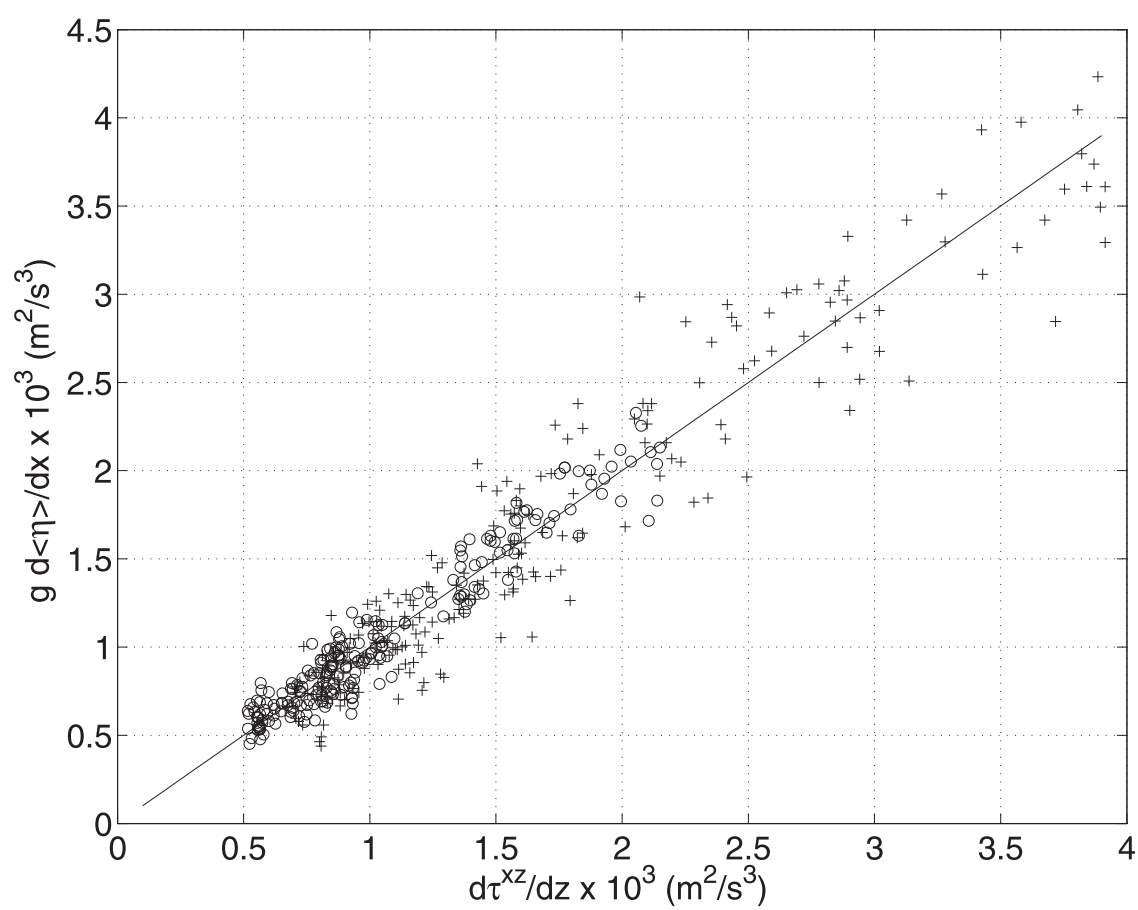

FIG. 19. Comparison of free surface pressure gradient and shear stress gradient calculated between stations 4 and 5 (plus signs) and stations 5 and 7 (open circles). The straight line represents the condition where the free surface pressure gradient balances the vertical stress gradient.

one would expect that the observed condition $q_{T} \approx q_{s}$ seen in Fig. 14 would not hold for the 10 fold variation in $F_{w}$ we observed at P2.5 during the December 2008 and February 2009 deployments. Unfortunately, the data do not allow us to distinguish between these possibilities since fits of the form $q_{T}=a F_{w}^{n}+b$ for $n=0.2$ and $n=0.5$ are quite similar and have nearly identical accuracy of prediction $\left(r^{2}=0.88\right)$. In like fashion, assuming a linear

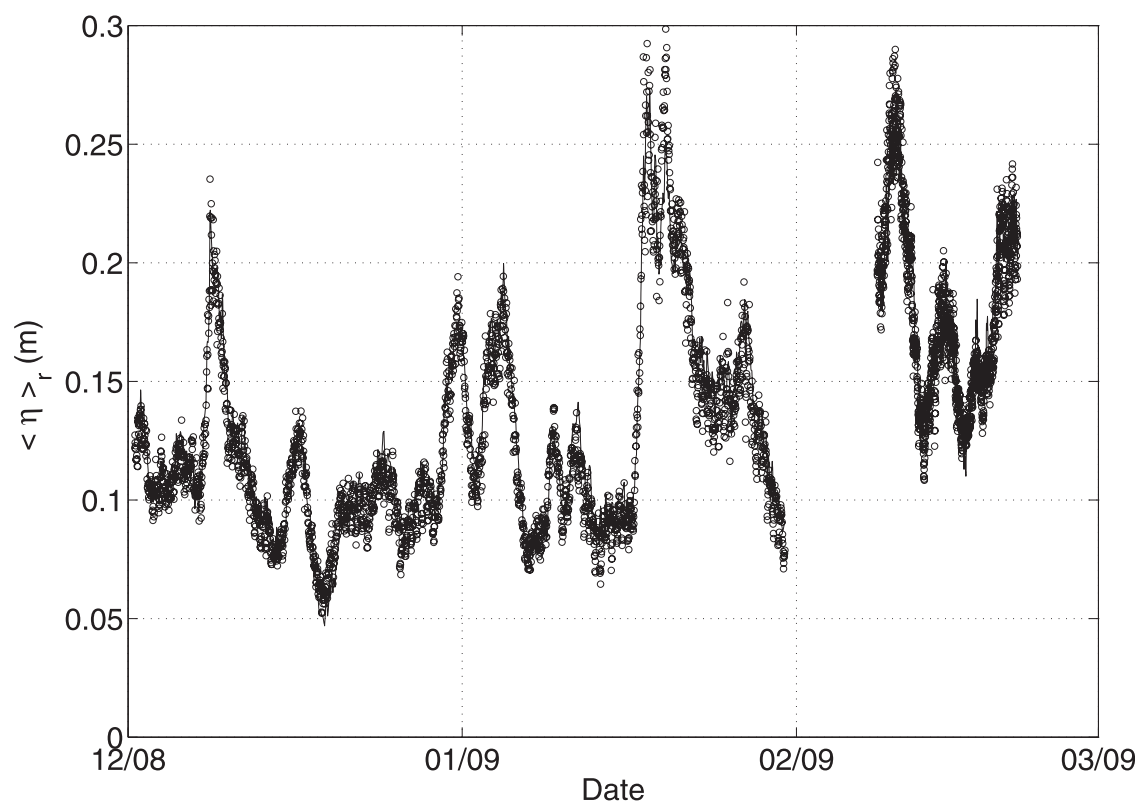

FIG. 20. Comparison between observed free surface set-up (open circles) and predicted (solid line) from (5) at backreef station P3. 


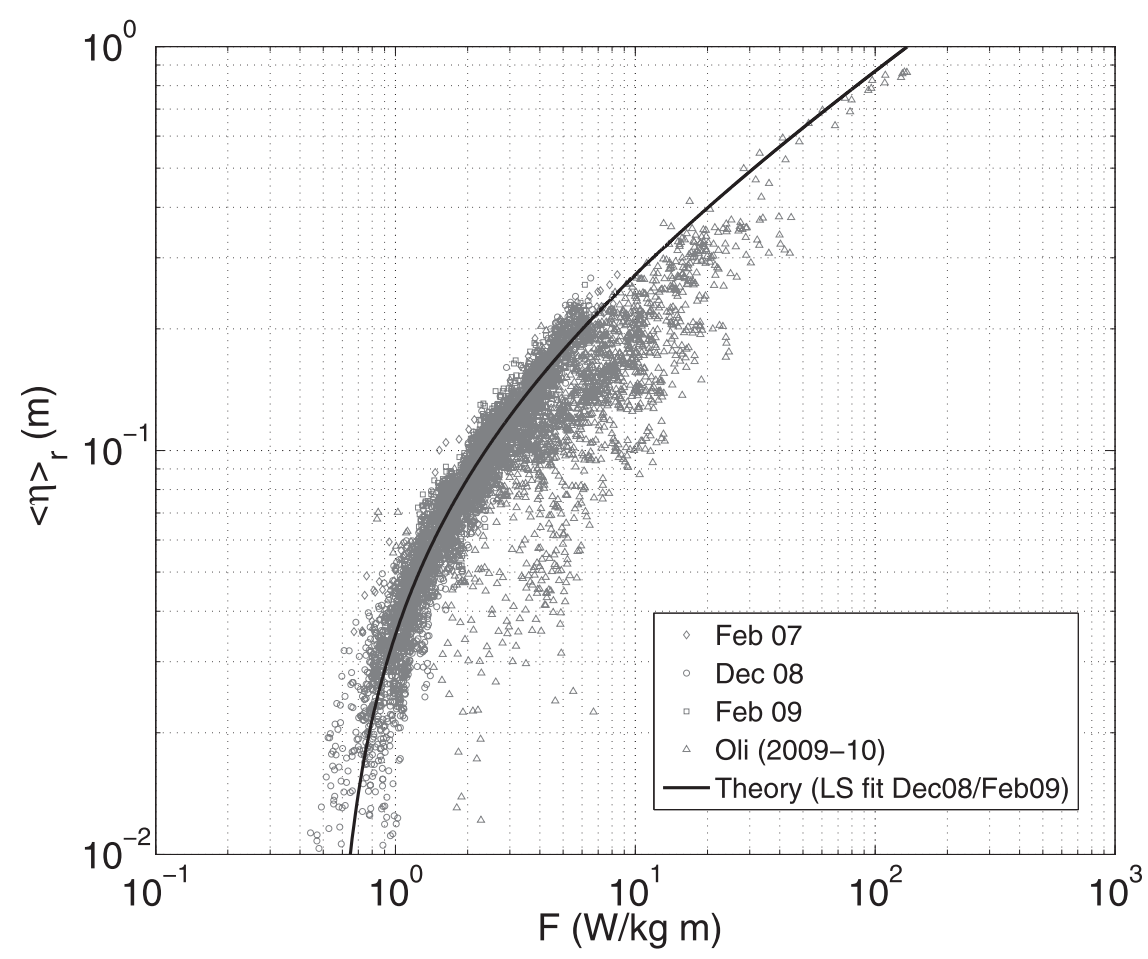

FIG. 21. Relationship between wave setup and unit shoreward wave energy flux derived from several datasets collected during austral summer: February 2007 (13 days, diamonds), December 2008 (60 days, open circles), February 2009 (13 days, squares), and December 2009-May 2010 including Cyclone Oli (134 days, triangles). The thick curve is predicted setup from (13), with $\gamma=0.98$ and $h_{r}=0.46 \mathrm{~m}$.

friction model (Symonds et al. 1995; Bonneton et al. 2007), would give $q_{T} \propto F_{w}^{4 / 5}$; a fit of this form to our data is only fractionally less accurate than either or with $r^{2}=0.87$. However, while analytically convenient, a linear friction model is likely only appropriate for weak mean flows in the presence of strong waves.

In any case, the setup in this steep reef system can be well predicted over a wide range of wave conditions from radiation stress theory including the simplest model of wave breaking, that is, that local wave height limit is proportional to the local depth. This behavior is interesting in light of the fact that, as seen in the laboratory measurements of Yao et al. (2013), wave breaking on steep reefs looks quite different from what is seen on flat beaches. As seen on the Moorea reef as well as in the laboratory, breaking on steep reef faces appears to involve a single plunging break followed by a turbulent bore that interacts with the shallow reef crest, propagates inshore, and dissipates. Unfortunately for very practical reasons, we do not have measurements in the region between the reef crest and where the waves first break, so why the simple breaking model works so well remains to be determined.
Acknowledgments. The authors are grateful for substantial field assistance from Johanna Rosman, Nick Nidzieko, Alyson Santoro, Sarah Giddings, Kristen Davis, Mike Murray, Jim Leichter, and Hunter Lenihan. We thank the staff of the U.C. Berkeley Gump Station on Moorea for logistical support, as well as Mark Merrifield, Janet Becker, Alex Sheremet, and Falk Feddersen for helpful discussions. The paper was substantially improved during review by comments from two anonymous reviewers. This work was supported by the National Science Foundation through the Physical Oceanography program (OCE-0622967) and the Moorea Coral Reef LTER site (OCE-0417412), and by the Singapore Stanford Partnership.

\section{APPENDIX}

\section{Definitions of Various Wave Quantities}

In this appendix we define a number of the wave quantities that appear in the body of the paper. The first of these are the total $q_{T}$, Eulerian $q_{E}$, and wave $q_{s}$, transports: 


$$
\begin{aligned}
q_{T} & =\langle q\rangle=\left\langle\int_{-h(x)}^{\eta} u d z\right\rangle \\
& =\int_{-h(x)}^{\langle\eta\rangle}\langle u\rangle d z+\left\langle\int_{-h(x)}^{\eta}(u-\langle u\rangle) d z\right\rangle=q_{E}+q_{w},
\end{aligned}
$$

where angle brackets represent wave averaging, such that "fast" motions at the time scale of gravity waves are filtered over an averaging period $T$, while retaining slower variations such as tides or infragravity waves (McWilliams et al. 2004)

$$
\langle f\rangle=\frac{1}{T} \int_{t_{0}}^{t_{0}+T} f d t .
$$

The second wave-averaged quantity appearing in (1) is the radiation stress, which is given as (Svendsen 2006)

$$
S_{\mathrm{xx}}=\rho\left\langle\int_{-h(x)}^{\eta}\left(u^{2}-w^{2}\right) d z\right\rangle+\frac{1}{2} \rho g\left\langle\eta^{2}\right\rangle .
$$

Usually, $S_{\mathrm{xx}}$ is calculated from some form of wave theory, most commonly Airy-Stokes linear wave theory, although values appropriate to cnoidal and solitary waves can be found in Svendsen (2006). We note that, for linear shallow water (LSW) waves,

$$
u_{\mathrm{LSW}}=\sqrt{g h} \frac{\eta}{h},
$$

which gives

$$
S_{\mathrm{xx}} \simeq \frac{3}{2} \rho g\left\langle\eta^{2}\right\rangle
$$

Note that it is independent of wave shape, although for sinusoidal waves of height $H\left\langle\eta^{2}\right\rangle=H^{2} / 8$, which gives the classical result

$$
S_{\mathrm{xx}}=\frac{3}{16} \rho g H^{2}
$$

for long waves. Likewise, using, the wave transport is

$$
q_{w}=\sqrt{\frac{g}{h}}\left\langle\eta^{2}\right\rangle
$$

which simplifies to $q_{w}=(1 / 8) \sqrt{g h} H^{2}$ for sinusoidal waves.

The final wave quantities of interest are the wave energy density

$$
E=\rho g \int_{0}^{\infty} S_{\eta \eta}(f) d f=\rho g\left\langle\eta_{w}^{2}\right\rangle,
$$

where $\eta_{w}=\eta-\langle\eta\rangle$ and, and the wave energy flux:

$$
F_{w}=\rho \int_{0}^{\infty} \int_{0}^{2 \pi} c_{g}(f) \hat{S}_{\eta \eta}(f, \theta) \cos \left(\theta-\theta_{r}\right) d f d \theta,
$$

where $\theta_{r}$ is the direction normal to the reef crest and the two power spectral densities appearing in (A8) and (A9) are related through the integration

$$
S_{\eta \eta}(f)=\int_{0}^{2 \pi} \hat{S}_{\eta \eta}(f, \theta) d \theta .
$$

If the wave energy flux at any frequency is concentrated in a narrow band centered at $\theta_{0}(f)$, (A9) can be integrated to produce

$F_{w} \simeq \rho \int_{0}^{\infty} c_{g}(f) S_{\eta \eta}(f) \cos \left[\theta_{0}(f)-\theta_{r}\right] d f$

Finally, linear wave theory (e.g., Svendsen 2006) gives velocities in the dominant wave direction as

$$
\begin{aligned}
& u_{\mathrm{rms}}(\sigma)=\left\{\int_{0}^{f_{c}} 4 \pi^{2} f^{2} S_{\eta \eta}(f) \frac{\cosh ^{2}[k h(\sigma+1)]}{\sinh ^{2}(k h)} d f\right\}^{1 / 2} \\
& w_{\mathrm{rms}}(\sigma)=\left\{\int_{0}^{f_{c}} 4 \pi^{2} f^{2} S_{\eta \eta}(f) \frac{\sinh ^{2}[k h(\sigma+1)]}{\sinh ^{2}(k h)} d f\right\}^{1 / 2},
\end{aligned}
$$

where the wavenumber $k=k(f, h)$ is determined from the linear dispersion relation and $\sigma$ is defined by (8).

\section{REFERENCES}

Bandet, M., 2009: Dynamics of wave-induced boundary layer over very rough boundaries: Field observations over a stretch of coral reef. Ph.D. dissertation, University of Hawaii at Manoa, 200 pp.

Bonneton, P., J. P. Lefebvre, P. Bretel, S. Ouillon, and P. Douillet, 2007: Tidal modulation of wave-setup and wave-induced currents on the Aboré coral reef, New Caledonia. J. Coastal Res., SI50, 662-766.

Booij, N., R. C. Ris, and L. H. Holthuijsen, 1999: A third generation wave model for coastal regions: I. Model description and validation. J. Geophys. Res., 104 (C4) 7649-7666.

Filipot, J. F., and K. F. Cheung, 2012: Spectral wave modelling in fringing reef environments. Coastal Eng., 67, 67-79.

Gordon, L., and A. Lohrmann, 2001: Near-shore Doppler current meter wave spectra. Proc. Fourth Int. Symp. on Ocean Wave Measurement and Analysis, WAVES2001, San Francisco, CA, ASCE, 33-43.

Gourlay, M. R., 1996: Wave set-up on coral reefs. 1. Set-up and wave-generated flow on an idealised two-dimensional reef. Coastal Eng., 27, 161-193.

— , and G. Colleter, 2005: Wave-generated flow on coral reefs An analysis for two-dimensional horizontal reef-tops with steep faces. Coastal Eng., 52, 353-387.

Grant, W. D., and O. S. Madsen, 1979: Combined wave and current interaction with a rough bottom. J. Geophys. Res., 84, 1797-1808. 
Gudmestad, O. T., and J. J. Connor, 1986: Engineering approximations to nonlinear deep water waves. Appl. Ocean Res., 8, 76-88.

Guza, R. T., and E. B. Thornton, 1980: Local and shoaled comparisons of sea surface elevations, pressures and velocities. J. Geophys. Res., 85 (C3), 1524-1530.

Hearn, C. J., 1999: Wave-breaking hydrodynamics within coral reef systems and the effect of changing relative sea level. J. Geophys. Res., 104 (C12), 30 007-30019.

Hench, J. L., J. J. Leichter, and S. G. Monismith, 2008: Episodic circulation and exchange in a wave driven coral reef lagoon system. Limnol. Oceanogr., 53, 2681-2694.

Herdman, L. M., 2012: Circulation, residence time, and retention in a tropical coral reef. Ph.D. thesis, Stanford University, 288 pp.

Holthuijsen, L. G., 2007: Waves in Oceanic and Coastal Waters. Cambridge University Press, 387 pp.

Jonsson, I. G., 1980: A new approach to oscillatory rough boundary layers. Ocean Eng., 7, 109-152.

Longuet-Higgins, M. S., and R. W. Stewart, 1962: Radiation stress and mass transport in gravity waves with application to 'surf beats.' J. Fluid Mech., 13, 481-504.

_ discussion, with applications. Deep-Sea Res., 11, 529-562.

Lowe, R. J., J. L. Falter, M. D. Bandet, G. Pawlak, M. J. Atkinson, S. G. Monismith, and J. R. Koseff, 2005: Spectral wave dissipation over a barrier reef. J. Geophys. Res., 110, C04001, doi:10.1029/2004JC002711.

— - _ S. G. Monismith, and M. J. Atkinson, 2009a: Wavedriven circulation of a coastal reef lagoon system. J. Phys. Oceanogr., 39, 873-893.

,,$---1 \ldots$, and $-2009 \mathrm{~b}$ : A numerical study of circulation in a coastal reef-lagoon system. J. Geophys. Res., 14, C06022, doi:10.1029/2008JC005081.

— C. Hart, and C. B. Pattiaratchi, 2010: Morphological constraints to wave-driven circulation in coastal reef-lagoon systems: A numerical study. J. Geophys. Res., 115, C09021, doi:10.1029/2009JC005753.

McWilliams, J. C., J. M. Restrepo, and E. M. Lane, 2004: An asymptotic theory for the interaction of waves and currents in coastal waters. J. Fluid Mech., 511, 135-178.

Mei, C. C., M. Stiassnie, and D. K.-P. Yue, 2005: Theory and Applications of Ocean Surface Waves, Part 1: Linear Aspects; Part 2: Nonlinear Aspects, Advanced Series on Ocean Engineering, Vol. 23, World Scientific, 1136 pp.

Miche, A., 1944: Mouvements ondulatoires de la mer en profondeur croissante ou décroissante. Application aux digues maritimes. Troisième partie. Forme et propriétés des houles limites lors du déferlement. Croissance des vitesses vers la rive. Ann. Ponts Chaussees, 114, 369-406.

Munk, W. H., and M. C. Sargent, 1948: Adjustment of Bikini Atoll to ocean waves. Trans. Amer. Geophys. Union, 29, 855-860.

Nelson, R. C., 1996: Hydraulic roughness of coral reef platforms. Appl. Ocean Res., 18, 265-274.

Nunes, V., and G. Pawlak, 2008: Observations of bed roughness of a coral reef. J. Coastal Res., 24, 39-50.

Nwogu, O., and Z. Demirbilek, 2010: Infragravity wave motions and runup over shallow fringing reefs. J. Waterw. Port Coastal Ocean Eng., 136, 295-305.

Péquignet, A. C. N., J. M. Becker, M. A. Merrifield, and J. Aucan, 2009: Forcing of resonant modes on a fringing reef during tropical storm Man-Yi. Geophys. Res. Lett., 36, L03607, doi:10.1029/ 2008GL036259.
,,--- , and S. J. Boc, 2011: The dissipation of wind wave energy across a fringing reef at Ipan, Guam. Coral Reefs, 30, $71-82$.

Raubenheimer, B., R. T. Guza, and S. Elgar, 1996: Wave transformation across the inner surf zone. J. Geophys. Res., 101 (C11), 25 589-25597.

,-- , and -2001 : Field observations of wave-driven setdown and setup. J. Geophys. Res., 106, 4629-4638.

Reidenbach, M. A., S. G. Monismith, J. R. Koseff, G. Yahel, and A. Genin, 2006: Boundary layer turbulence and flow structure over a fringing coral reef. Limnol. Oceanogr., 51, 1956-1968.

Roelvink, D., A. Reniers, A. van Dongeren, J. van Thiel de Vries, R. McCall, and J. Lescinski, 2009: Modelling storm impacts on beaches, dunes, and barrier islands. Coastal Eng., 56, $1133-1152$.

Rosman, J. H., and J. L. Hench, 2011: A framework for understanding drag parameterizations for coral reefs. J. Geophys. Res., 116, C08025, doi:10.1029/2010JC006892.

Ruessink, B. G., J. R. Miles, F. Feddersen, R. T. Guza, and S. Elgar, 2001: Modeling the alongshore current on barred beaches. J. Geophys. Res., 106 (C10), 22 451-22 463.

Sheremet, A., R. T. Guza, S. Elgar, and T. H. C. Herbers, 2002: Observations of nearshore infragravity waves: Part 1: Seaward and shoreward propagating components. J. Geophys. Res., 107 (C8), doi:10.1029/2001JC000970.

Shinn, E. A., 1963: Spur and groove formation on the Florida reef tract. J. Sediment. Res., 33, 291-303.

Storlazzi, C. D., J. B. Logan, and M. E. Field, 2003: Quantitative morphology of a fringing reef tract from high-resolution laser bathymetry: Southern Molokai, Hawaii. Geol. Soc. Amer. Bull., 115, 1344-1355.

Strong, B., B. H. Brumley, E. A. Terray, and G. W. Stone, 2000: The performance of ADCP-derived wave spectra and comparison with other independent measurements. Proc. Oceans 2000, Providence, RI, MST/IEEE, 1195-1203.

Svendsen, I. A., 2006: Introduction to Nearshore Nydrodynamics. World Scientific, $722 \mathrm{pp}$.

Symonds, G., K. P. Black, and I. R. Young, 1995: Wave-driven flow over shallow reefs. J. Geophys. Res., 100 (C2), 26392648.

- L. Zhong, and N. A. Mortimer, 2011: Effects of wave exposure on circulation in a temperate reef environment. J. Geophys. Res., 116, C09010, doi:10.1029/2010JC006658.

Taebi, S., R. J. Lowe, C. B. Pattiaratchi, G. N. Ivey, G. Symonds, and R. Brinkman, 2011: Nearshore circulation in a tropical fringing reef system. J. Geophys. Res., 116, C02016, doi:10.1029/ 2010JC006439.

Tait, R. J., 1972: Wave set-up on coral reefs. J. Geophys. Res., 77, 2207-2211.

Vetter, O., J. M. Becker, M. A. Merrifield, A. C. Pequignet, J. Aucan, S. J. Boc, and C. E. Pollock, 2010: Wave setup over a Pacific Island fringing reef. J. Geophys. Res., 115, C12066, doi:10.1029/2010JC006455.

Yao, Y., E. Lo, Z. Huang, and S. Monismith, 2009: An experimental study of wave-induced setup over a horizontal reef with an idealized ridge. Proc. OMAE09 28th Int. Conf. on Ocean, Offshore and Arctic Engineering, Honolulu, HI, ASCE, 383389, doi:10.1115/OMAE2009-79224.

, Z. H. Huang, S. G. Monismith, and E. Y. M. Lo, 2013: Characteristics of monochromatic waves breaking over fringing reefs. J. Coastal Res., 29, 94-104. 